Check for updates

Cite this: Chem. Sci., 2019, 10, 7132

๑ All publication charges for this article have been paid for by the Royal Society of Chemistry

Received 11th March 2019

Accepted 24th June 2019

DOI: 10.1039/c9sc01201j

rsc.li/chemical-science

\section{Towards high energy density lithium battery anodes: silicon and lithium}

\author{
Bin Zhu, (D) Xinyu Wang, Pengcheng Yao, Jinlei Li and Jia Zhu (DD*
}

Silicon and lithium metal are considered as promising alternatives to state-of-the-art graphite anodes for higher energy density lithium batteries because of their high theoretical capacity. However, significant challenges such as short cycle life and low coulombic efficiency have seriously hindered their practical applications. In the past decades, various strategies have been proposed to address the major problems of $\mathrm{Si}$ and $\mathrm{Li}$ anodes. In this review, we summarize the understanding on $\mathrm{Si}$ and $\mathrm{Li}$ anodes, highlight the recent progress in the development and introduce advanced characterization techniques. We also indicate the remaining challenges of $\mathrm{Si}$ and $\mathrm{Li}$ anodes requiring more efforts for future widespread applications. We expect that this review provides an overall picture of the recent progress and inspires more efforts in the fundamental understanding and practical applications of Si and Li anodes.

\section{Introduction}

Energy storage is crucial in energy processes coupled with renewable energy generation and usage. Lithium ion batteries (LIBs) play a significantly important role in various energy storage technologies because of their high energy density. ${ }^{\mathbf{1 - 4}}$ Since the first commercial LIB came out in 1991, it has played a critical role in enabling the widespread availability of portable electronics and emergence of electric vehicles. ${ }^{5}$ However, traditional electrode materials (such as commercial lithium cobalt oxide $\left(\mathrm{LiCoO}_{2}\right)$ cathodes and graphite anodes) have approached their theoretical capacities, limiting the energy density of LIBs $\left(\sim 260 \mathrm{~W} \mathrm{~h} \mathrm{~kg}^{-1}\right)^{6}$ (Fig. 1a). Lithium-based

National Laboratory of Solid State Microstructures, College of Engineering and Applied Sciences, Jiangsu Key Laboratory of Artificial Functional Materials, Nanjing University, Nanjing 210093, P. R. China. E-mail: jiazhu@nju.edu.cn batteries with advanced performance and low cost are expected to come from new battery chemistries, mainly based on different storage mechanisms at the material level, and different configurations at the cell and system level. ${ }^{7}$

To figure out how to improve the energy density, let us first go back to the definition of energy density of LIBs. For a typical LIB, the electrochemical voltage $(V)$ based cathode/anode and the specific capacity $(C)$ of electrodes determined its energy density $(E)$ like below:

$$
E=C_{\mathrm{c}} C_{\mathrm{a}} /\left(C_{\mathrm{a}}+C_{\mathrm{c}}\right)\left(V_{\mathrm{c}}-V_{\mathrm{a}}\right)
$$

It clearly illustrates that increasing the working voltage of a LIB or capacity of electrodes can improve its energy density. So in the case of anodes, silicon ( $\mathrm{Si}$ ) and lithium (Li) are the two most promising candidates on account of their high specific capacities. Through calculation, it was found that by using $\mathrm{Si}$ / carbon and $\mathrm{Li}$ anodes to replace graphite coupled with Li-rich or

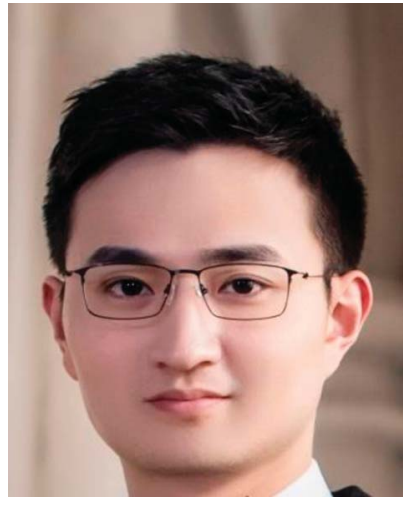

Bin $Z$ hu received his B.S. degree in materials physics from Nanjing University in 2013 and his Ph.D. in Materials Science and Engineering from Nanjing University in 2018. He is currently a research scientist working under the direction of Professor Jia Zhu. His research interests include energy storage and water treatment.

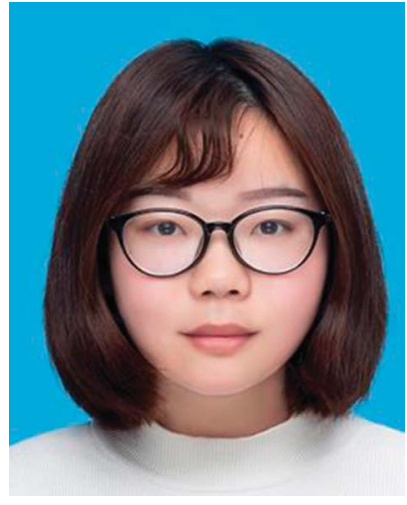

Xinyu Wang received her B.S. degree in Materials Science and Engineering from Hefei University of Technology in 2018. She joined Prof. Jia Zhu's group at Nanjing University to pursue her M.S. degree. Her current research interest is lithium batteries. 
a

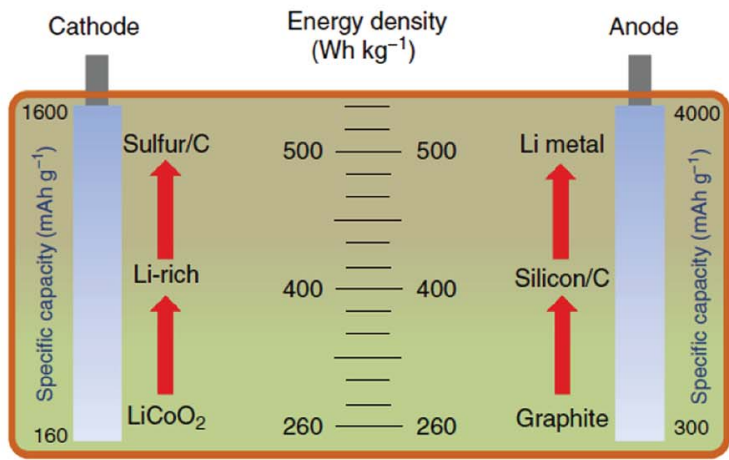

b

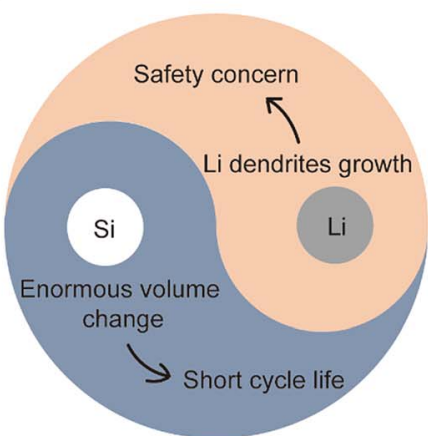

Fig. 1 (a) Specific energy densities of LIBs based on different cathode and anode materials. Reproduced with permission. ${ }^{6}$ Copyright (2018) Nature Publishing Group. (b) Correlations among different challenges in Si and Li metal anodes, originating from huge volumetric changes and Li dendrite growth.

sulfur cathodes, the energy density of a LIB will reach $400 \mathrm{~W} \mathrm{~h}$ $\mathrm{kg}^{-1}$ and $500 \mathrm{~W} \mathrm{~h} \mathrm{~kg}{ }^{-1}$, respectively (Fig. 1a). However, complicated and different reaction mechanisms of $\mathrm{Si}$ and $\mathrm{Li}$ anodes during cycling compared with graphite lead to many

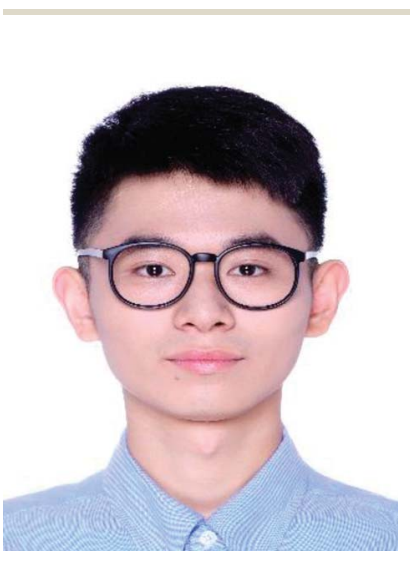

Pengcheng Yao received his B.S. in Materials Science and Engineering from Tianjin University in 2016 and his M.S. from Columbia University in 2018. He is currently a Ph.D. candidate at Nanjing University working under the direction of Professor Jia Zhu. His research interests include lithium batteries and photothermal conversion.

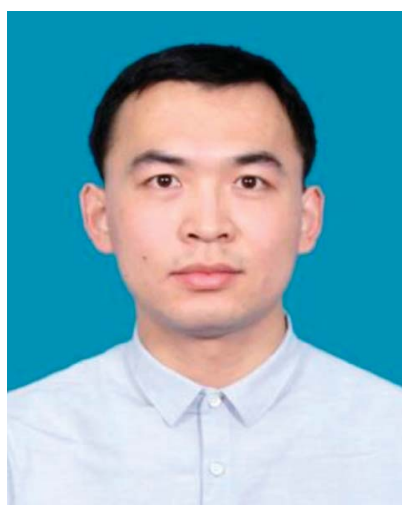
Jinlei $L i$ received his B.S. from Central South University in 2015 and his M.S. degree from Nanjing University in 2018 under the supervision of Prof. Jia Zhu. His current research interest is photothermal conversion. hurdles for their practical applications such as enormous volumetric changes and dendrite growth ${ }^{8-20}$ (Fig. 1b).

In recent years, growing efforts have been made to address these problems. For example, various nanostructure designs have been proposed to achieve a stable cycle life for the $\mathrm{Si}$ anode. There are excellent reviews covering the exciting progress so far. ${ }^{21-25}$ However, problems such as low coulombic efficiency and high cost still limit its applications. Therefore, in this perspective report, we not only summarize the important progress of Si and Li anodes, but also introduce and discuss the remaining essential issues towards their applications. Our main objective is to illustrate the fundamental strategies to improve the electrochemical performance of $\mathrm{Si}$ and $\mathrm{Li}$ anodes, while providing inspiration for future developments.

\section{Si anode}

\subsection{Fundamental problems of the Si anode}

As one Si atom can bind with four Li ions, Si not only possesses a high theoretical capacity of $\sim 4200 \mathrm{~mA} \mathrm{~h} \mathrm{~g}^{-1}$ (ten times that of the commercial graphite anode) but also undergoes $\sim 300 \%$

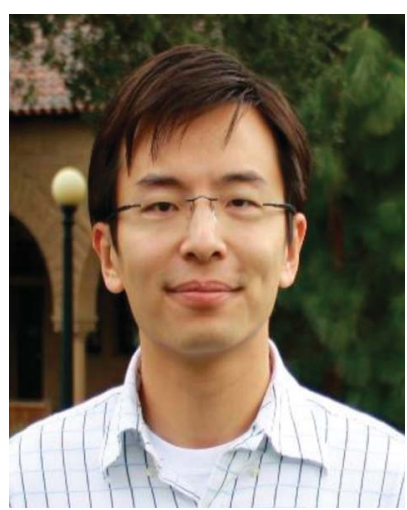

Jia Zhu received his B.S. in physics from Nanjing University in China in 2003 and his M.S. and Ph.D. in Electrical Engineering from Stanford University in 2006 and 2010 respectively. He went on to work as a postdoctoral scholar at the University of California, Berkeley. In 2013, he became a professor in the College of Engineering and Applied Sciences at Nanjing University. He leads a group of researchers working on nanomaterials for energy conversion and storage. He has received the "Tan Kah Kee Young Scientist" Award (2018), Dupont Young Professor Award (2016) and MIT Tech Review TR35 award (2016). 
volumetric change during lithiation/delithiation in the meantime. ${ }^{9}$ It's well known that crystalline Si transforms into an amorphous $\mathrm{Li} / \mathrm{Si}$ alloy with anisotropic volumetric expansion in the initial lithiation while the volume of Si shrinks during delithiation. ${ }^{13,26,27}$ Such enormous volume fluctuation results in self-pulverization and fracture during cycling (Fig. 2a). If the $\mathrm{Si}$ electrode is composed of Si particles, a huge volume change leads to detachment of particles and loss of electrochemical contact (Fig. 2b). These two problems both result in dramatic capacity decay in short cycles. ${ }^{28,29}$ Besides, the solid electrolyte interphase (SEI) formed on the Si anode surface due to the reduction of commonly employed organic electrolytes is unstable..$^{4,30,31}$ The high coulombic efficiency (CE) and cycle stability of anodes are closely relevant to a stable SEI. As shown in Fig. 2c, with the huge volumetric change of the Si anode during electrochemical cycling, the formed SEI will break and expose the fresh electrode surface to electrolyte, leading to continuous growth of a new SEI. This not only consumes much electrolyte and $\mathrm{Li}$ but also increases the distance of $\mathrm{Li}$ ion diffusion, leading to a low $\mathrm{CE}$ and material degradation. To solve the problems mentioned above, various strategies have been proposed such as structure design, employing new electrolyte additives, binder modification and using Si/graphite composite materials, which will be briefly discussed in the following part.

\subsection{Solutions for the problems of the $\mathrm{Si}$ anode}

2.2.1 Nanostructure design. Because of enhanced mechanical properties at the nanoscale, the development of nanostructured Si has been a feasible strategy to relieve volume expansion. ${ }^{32-41}$ It is crucial to understand the critical fracture size, below which the expansion induced strain will be accommodated without cracking. According to much systematic investigation before such as theoretical simulation, scanning electron microscopy (SEM), and in situ transmission electron microscopy (TEM), the critical fracture size of crystalline $\mathrm{Si}$ particles is estimated to be $\sim 150 \mathrm{~nm},{ }^{42}$ while that of nanowires is $300-400 \mathrm{~nm}^{43}$ In view of this, various designs of nanostructures have been proposed to resolve pulverization. Cui's group introduced $\mathrm{Si}$ nanowires as an anode to overcome the strain problem to avoid fracture ${ }^{44}$ (Fig. 3a). The close link between nanowires and the current collector enables good electrical contact and short Li ion diffusion. Yushin's group utilized a bottom-up assembly way to synthesis $\mathrm{Si}-\mathrm{C}$ porous composites as anodes $^{\mathbf{4 5}}$ (Fig. 3b). The rigid and robust $\mathrm{Si}$ spheres are connected closely with the $\mathrm{C}$ framework, providing a rapid access of $\mathrm{Li}$ ions to the $\mathrm{Si}$ spheres. Moreover, large internal porosity inside the electrode can accommodate the volumetric expansion of Si during lithiation. To stabilize the SEI during cycling, Liu et al. designed a "yolk-shell" structure consisting of $\sim 100 \mathrm{~nm}$ Si nanoparticles as the yolk coated with $\sim 10 \mathrm{~nm}$ amorphous carbon as the shell $^{46}$ (Fig. 3c). The void between the yolk and shell can provide enough space for $\mathrm{Si}$ expansion without breaking the carbon shell while the carbon shell not only improves the electric conductivity of whole electrodes, but also stabilizes the SEI formed outside the carbon shell.

2.2.2 Electrolyte additives. Electrolyte plays a critically important role in $\mathrm{Si}$ anode cycling. Adding additives into the electrolyte would be beneficial for passivating the interface between $\mathrm{Si}$ and electrolyte. ${ }^{\mathbf{4 7 , 4 8}}$ A mechanically and chemically stable SEI is the key to improve the cycle stability of the Si anode. As reported before, electrolyte additives such as vinylene carbonate (VC), fluroethylene carbonate (FEC) and lithium difluoro(oxalate) borate (LiDFOB) have been introduced into the electrolyte for the Si anode, among which FEC shows great promise. In a common electrolyte system (ethylene carbonate (EC)/diethyl carbonate (DEC)), FEC degrades first to form a SEI mainly containing lithium fluoride (LiF) at higher voltage. It not only can suppress the continuous degradation of EC/DEC, but also adsorb other organic SEI components through the strong binding of $\mathrm{F}-\mathrm{Li}$ according to the density functional theory (DFT). ${ }^{49}$ Both of them enable a stable SEI during cycling for the Si anode. Horowitz et al. systematically studied the interaction of EC and FEC in different electrolyte mixtures for an amorphous Si anode through sum frequency generation vibrational spectroscopy and $a b$ initio molecular dynamics simulations ${ }^{\mathbf{4 7}}$ (Fig. 3d). They found that the FEC additive can lead to the reorientation of EC molecules to form an ordered, up-right orientation of electrolytes on the Si surface and it became the dominant species on the surface when its concentration increased above $20 \mathrm{wt} \%$ according to the $a b$ initio molecular dynamics simulations (Fig. 3e). It provided good SEI formation for the Si anode with optimized additive design. Whatever,

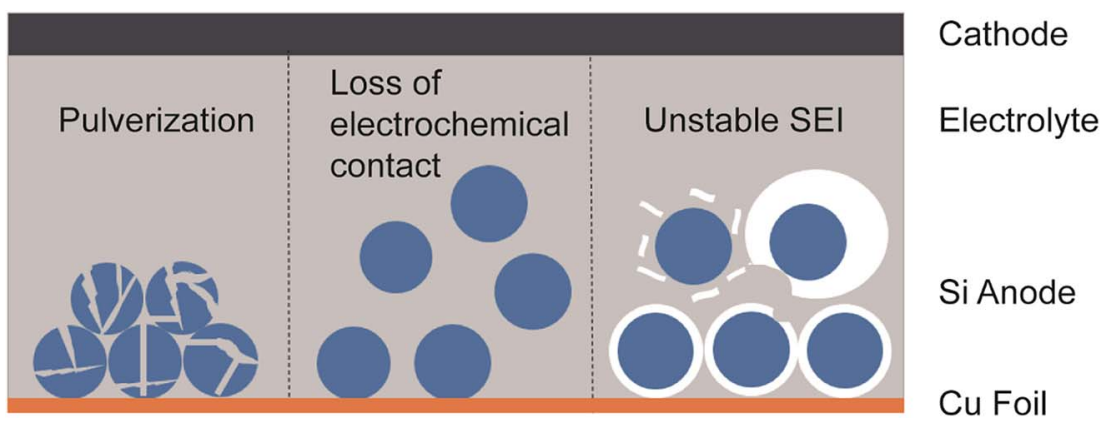

Fig. 2 The main fundamental problems resulting from the huge volumetric change of the Si anode during cycling. 
a
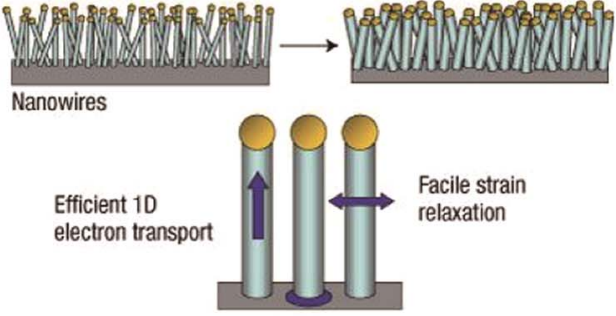

Good contact with current collector $b$

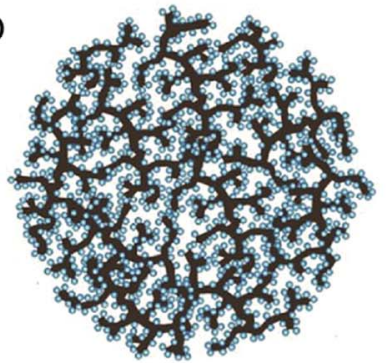

C

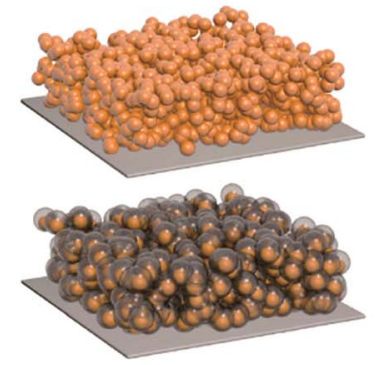

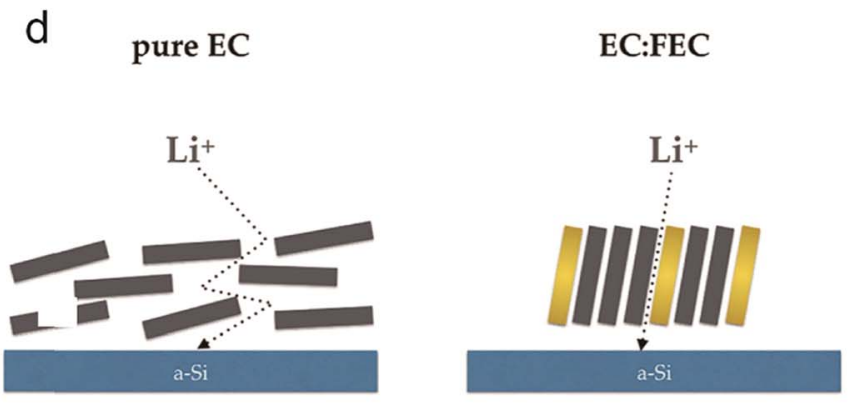

e
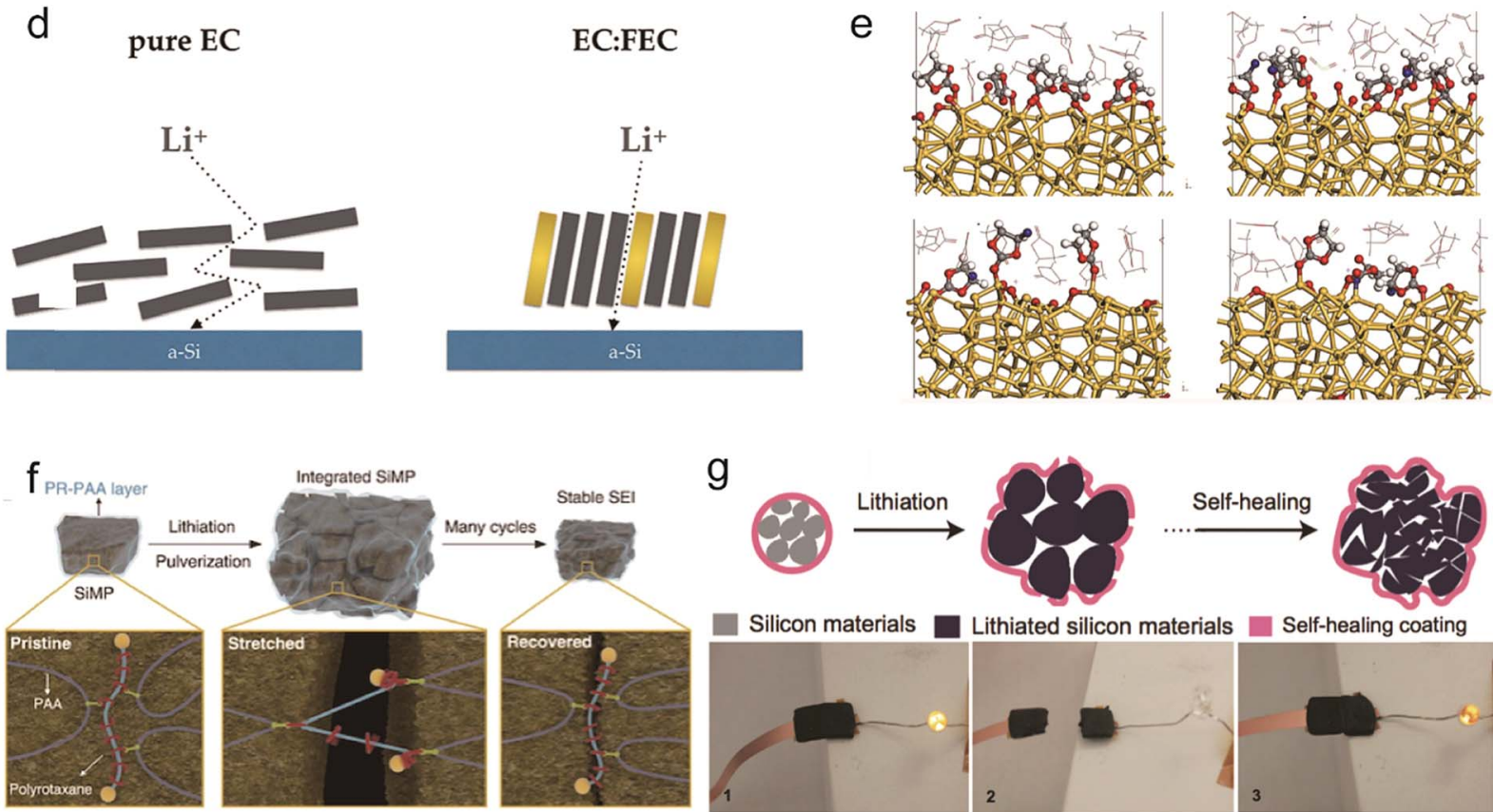

Stable SEI

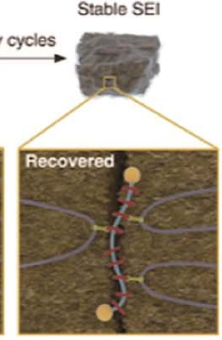

g
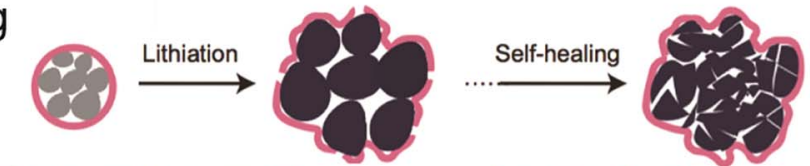

Silicon materials
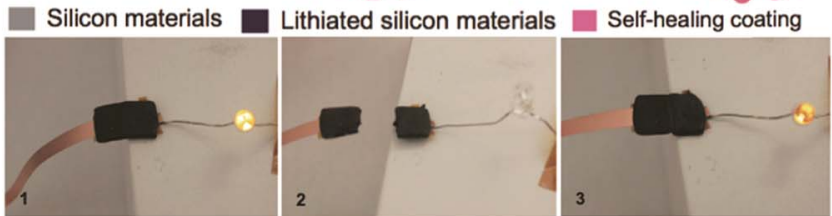

Fig. 3 Solutions for fundamental problems of silicon anodes: nanostructure design. $(a-c)$ Schematic of silicon nanowires. Reproduced with permission. ${ }^{44}$ Copyright (2008) Nature Publishing Group (a). Si-C nanocomposite granule formation through hierarchical bottom-up assembly. Reproduced with permission. ${ }^{45}$ Copyright (2010) Nature Publishing Group (b). A Si@voidaC electrode for a stable solid electrolyte interphase. Reproduced with permission. ${ }^{46}$ Copyright (2012) American Chemical Society (c). Electrolyte additives. (d and e) Fluoroethylene carbonate as a directing agent (d). Snapshots at approximately 50 ps of simulation time for the models with $20 \mathrm{wt} \%, 40 \mathrm{wt} \%, 50 \mathrm{wt} \%$ and pure FEC (e). (d and e) Reproduced with permission. ${ }^{47}$ Copyright (2017) American Chemical Society. Binder design. (f and g) PR-PAA binder to dissipate the stress during repeated volume changes of SiMPs. Reproduced with permission. ${ }^{54}$ Copyright (2017) Science. (f) The self-healing electrode. Reproduced with permission. ${ }^{55}$ Copyright (2013) Nature Publishing Group (g).

suitable electrolyte additives and their concentration added can be beneficial for the stable cycling of Si anodes.

2.2.3 Binder design. Binder is critical for fabricating slurry and maintaining the integrity of the electrode structure. In common, alginate, poly(acrylic acid), polyimide and carboxymethyl cellulose (CMC) have been used as binders for $\mathrm{Si}$ anodes. $^{50-52}$ To relieve the large volumetric change of the $\mathrm{Si}$ anode, it's necessary to exploit binders with good electronic conductivity, mechanical properties and binding affinity with $\mathrm{Si}^{53,54}$ Recently, Sunghun Choi et al. proposed incorporation of $5 \mathrm{wt} \%$ polyrotaxane into poly(acrylic acid) binder with an extraordinary elasticity to protect Si particles from disintegration during cycling. ${ }^{54}$ For example, when the Si anode pulverizes, the ring sliding of polyrotaxanes makes $\mathrm{Si}$ particles coalesce, which is critical for preserving the electrode morphology (Fig. 3f). With this new binder, the full-cell
$\mathrm{LiNi}_{0.8} \mathrm{Co}_{0.15} \mathrm{Al}_{0.05} \mathrm{O}_{2} \mid \mathrm{Si}$ presented $98 \%$ retention of the original capacity after 50 cycles with an average CE of $99.92 \%$. Because of the fracture of Si microparticles, applying a binder of selfhealing polymer can overcome the short life of the cell. Wang et al. proposed a thin layer of hydrogen-bond-directed selfhealing polymer coated on Si microparticles as the binder. ${ }^{55}$ When cycling, as Si microparticles fracture due to volumetric change-induced stress, the stretchable self-healing binder will spontaneously repair the cracks of the Si electrode to achieve stable cycling (Fig. 3g). With this self-healing binder, it shows a more stable cycle performance with capacity up to $2000 \mathrm{~mA} \mathrm{~h}$ $\mathrm{g}^{-1}$ after 100 cycles at a current density of $0.4 \mathrm{~A} \mathrm{~g}^{-1}$.

2.2.4 Si-based composite materials. Si-based composite materials such as Si/graphite and $\mathrm{Si}$ alloy composites are attracting much attention for the development of high performance Si anodes, because of the good electrical/ionic properties 
of composite materials. For example, graphite additives, which possess good electrical conductivity and mechanical properties, have shown obvious advantages for improving Si electrodes, not only by enhancing the electrical conductivity, but also in some cases, by buffering the volume change of Si during cycling. Recently, Jaephil Cho's group proposed a hybrid Si anode via incorporation of a uniformly implanted amorphous Si nanolayer and edge-site-activated graphite. ${ }^{56}$ The main procedure contains nickel (Ni) adsorption and chemical vapor deposition (CVD) (Fig. 4a), which finally result in Si/edge-activated graphite (SEAG). This Si/graphite composite anode not only possesses enhanced kinetics for $\mathrm{Li}^{+}$but also satisfies the aforementioned industrial electrode conditions. Therefore, the composite anode presents a high initial CE of $93.8 \%$. Besides, when pairing with the $\mathrm{LiCoO}_{2}$ cathode, the full cell exhibits a high energy density of $1060 \mathrm{~W} \mathrm{~h} \mathrm{~L}^{-1}$. Zhang et al. also proposed a 3D Si composite with a multilayer carbon matrix and decorated with conductive $\mathrm{Cu}$ agents $^{57}$ (Fig. 4b). Fundamentally, the carbon shell formed on the surface of Si can not only improve the conductivity but also alleviate side reactions. Besides, $\mathrm{Cu}$ particles decorated in the carbon matrix can also further improve the conductivity. Therefore, the as-prepared Si composite anode exhibits a high rate performance of $1035 \mathrm{~mA} \mathrm{~h} \mathrm{~g}^{-1}$ at $4 \mathrm{~A} \mathrm{~g}^{-1}$. Li et al. reported a $\mathrm{Si} /$ graphite composite anode through modified nano/microstructured $\mathrm{Si}$ with boron doping and carbon nanotube wedging $^{58}$ (Fig. 4c). Here, the graphite can act as a tough framework for a high loading of the Si anode which can reach $11.2 \mathrm{mg} \mathrm{cm}^{-2}$. With the Si/graphite composite anode paired with the NCM cathode, the full cell showed an excellent cycle performance with a capacity retention of $82.5 \%$ after 300 cycles.

$\mathrm{Si}$ has a relatively low electrical conductivity and $\mathrm{Li}$ ion conductivity, so alloying with a more highly conductive element is an effective way to improve the electrochemical performance of the Si anode. Recently, Stokes et al. proposed an axially heterostructured nanowire consisting of alternating segments of $\mathrm{Si}$ and Ge as the anode to greatly improve the rate performance of cells. $^{29}$ The $\mathrm{Si} / \mathrm{Ge}$ nanowires were synthesized through an injection of phenyl silane with Sn as the seed on stainless steel. During cycling, the original heterostructured nanowires gradually transformed into a porous network of homogeneously alloyed Si/Ge ligaments (Fig. 4d). Because of the greater electrical conductivity and higher Li diffusivity by utilizing Ge alloyed with $\mathrm{Si}$, the obtained electrode exhibits an exceptional rate performance, whereas the discharge capacity reached 613 $\mathrm{mA} \mathrm{h} \mathrm{g}^{-1}$ at a rate of $10 \mathrm{C}$ (Fig. $4 \mathrm{~d}$ ).

\subsection{Remaining problems for $\mathrm{Si}$ anodes}

Though much progress has been achieved for $\mathrm{Si}$ anodes as illustrated above, there still remain some problems for their commercialization such as high cost and low initial coulombic efficiency. ${ }^{59,60}$ Recently, many groups made some efforts towards these issues. To reduce the cost of the $\mathrm{Si}$ anode, it's found that cost-effective sources can replace high cost $\mathrm{Si}$ materials to produce Si anodes. As shown in Fig. 5a, rice husk is used as a source to synthesize porous $\mathrm{Si}$ anodes because it contains $15-20$ wt $\%$ silica. ${ }^{61}$ Considering the massive production of rice with 100 million tons every year, it's exactly a good source candidate for Si anodes. Recently, Zhu's group demonstrated that low grade $\mathrm{Si}$ from industry can be an attractive low-cost source for scalable production of Si anodes. ${ }^{62}$ The annual global production of metallurgical-grade silicon (M$\mathrm{Si}, \sim 98 \mathrm{wt} \% \mathrm{Si}, \mathbf{\$ 1} \mathrm{kg}^{-1}$ ) and ferrosilicon (F-Si, $83.4 \mathrm{wt} \% \mathrm{Si}$, $\$ 0.6 \mathrm{~kg}^{-1}$ ), which are two kinds of low grade $\mathrm{Si}$, is over six million tonnes. Si nanoparticles with a controlled size $(<150$ $\mathrm{nm}$, critical fracture size of crystalline Si nanoparticles) can be produced on a large scale through a facile mechanical milling process (Fig. 5b). It is found that, for F-Si sources, inactive $\mathrm{FeSi}_{2}$, serving as a buffer layer to alleviate the volume change of Si during cycling, is formed in Si nanoparticles during milling, whereas nanoparticles produced from M-Si sources possess higher capacity and better kinetic properties due to higher purity source materials and better electronic transport properties. On the basis of low grade Si, Zhu's group also developed a process for fabricating Si anodes with varying controllable porosity, morphology and purity through convenient procedures such as acid etching and ball milling. ${ }^{63-65}$ The series of studies for low grade Si provide a new path for the scalable production of Si anodes.

Initial coulombic efficiency, representing the ratio of discharge capacity and charge capacity, is an important parameter to evaluate the performance of electrodes. Because the nanostructured $\mathrm{Si}$ anode always possesses a high specific surface area, more SEI forms in the first lithiation, leading to a relatively low initial CE (50-80\%) compared with that of graphite $(>90 \%)$. Prelithiation has been proposed as an exciting strategy to improve the initial CE of Si anodes. Yang's group demonstrated a stable $\mathrm{Li}$ source reagent in air with the $\mathrm{Si}$ / polymer/lithium anode trilayer structure, which was then in situ prelithiated in Si after dissolving the polymer inside the cell. ${ }^{66}$ With the unique design, they achieved over $100 \%$ initial CE for Si anodes.

Zhao et al. proposed $\mathrm{Li}_{x} \mathrm{Si}-\mathrm{Li}_{2} \mathrm{O}$ core-shell particles as a prelithiation reagent to achieve a high capacity with high initial $\mathrm{CE}^{67}$ (Fig. 5d). Because of the protection of the $\mathrm{Li}_{2} \mathrm{O}$ shell, the nanoparticles are processible in a slurry under dry-air conditions. Through this method prelithiated Si anodes achieved a high initial CE of $>94 \%$.

Moreover, designing secondary structures with a protective shell between $\mathrm{Si}$ and electrolyte is another effective way to achieve high initial CE. Cui's group proposed many various designs in this aspect such as pomegranate-like Si anodes and conformal graphene cages surrounding Si micro particles. ${ }^{41,68}$ Recently, Minseong Ko et al. demonstrated that a Si-nanolayerembedded graphite/carbon anode presents a high first CE of $92 \%$ and stable cycling (96\% retention after 100 cycles) ${ }^{69}$ (Fig. 5e). A $20 \mathrm{~nm}$-thick Si nanolayer is grown in the inner pores of graphite particles via the chemical vapor deposition (CVD) method, so a thin layer can relieve mechanical stress and achieve fast Li diffusion during cycling. Meanwhile, a homogeneous carbon layer is coated on the Si nanolayer to promote electric conductivity and stabilize the SEI.

In summary, in the past decades, much progress has been achieved to address the volume change of the $\mathrm{Si}$ anode. 

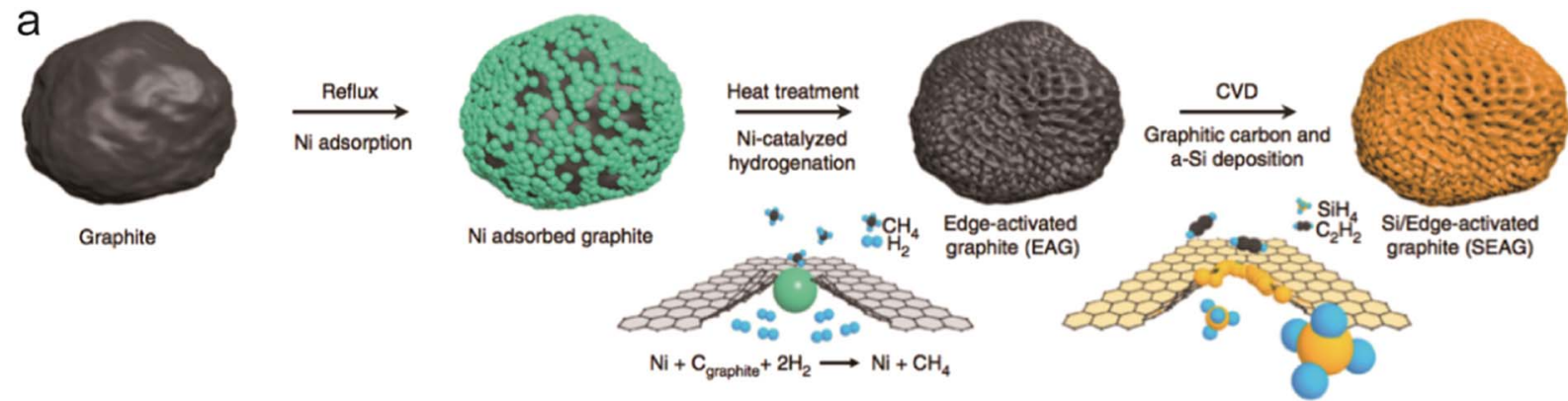

b

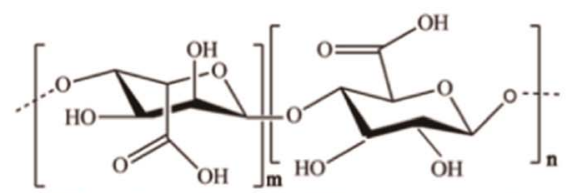

(G) guluronic

(M) mannuronic

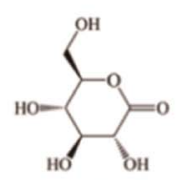

glucolactone

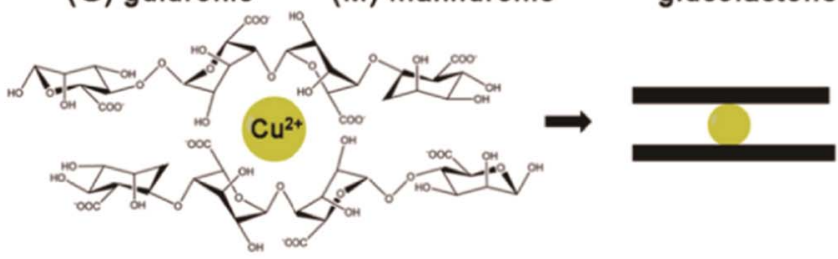

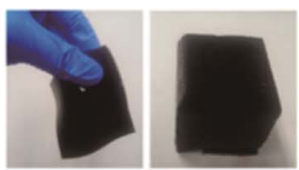
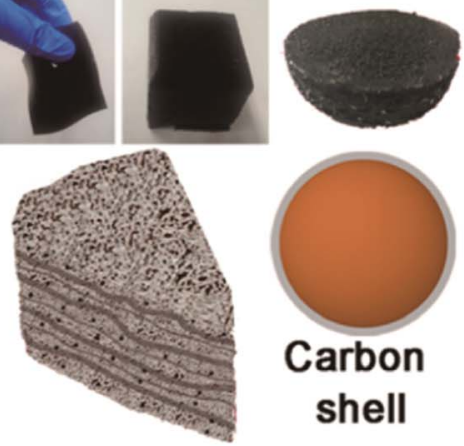

C
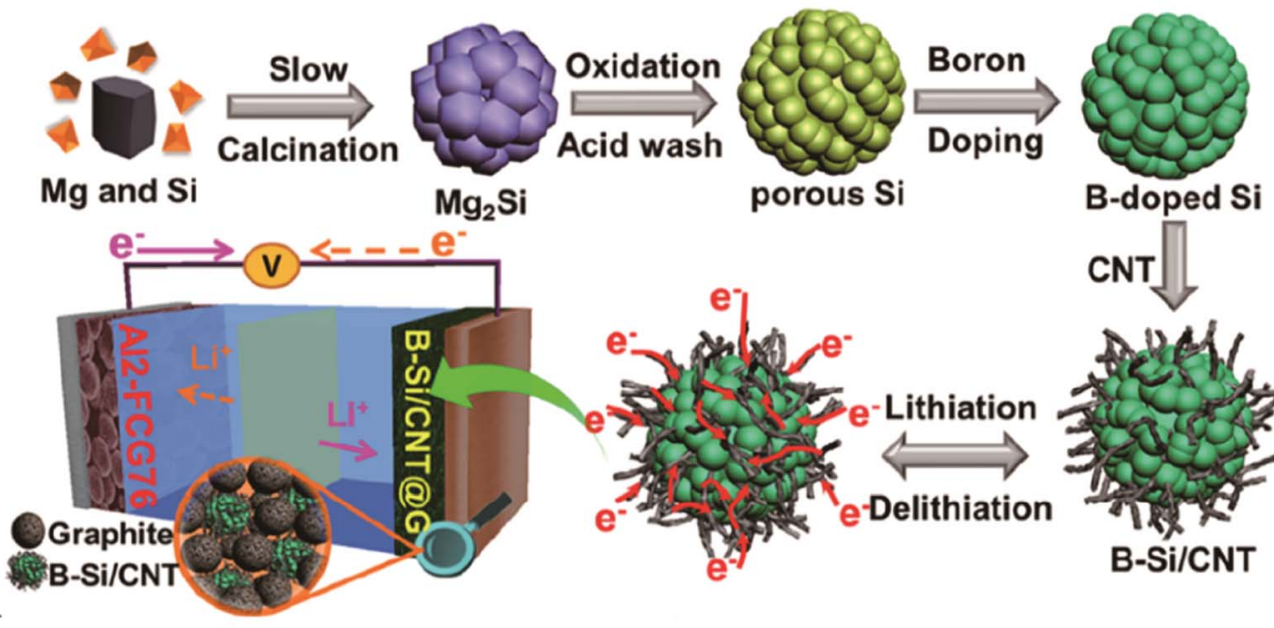

-Lithiation

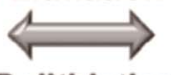
Delithiation
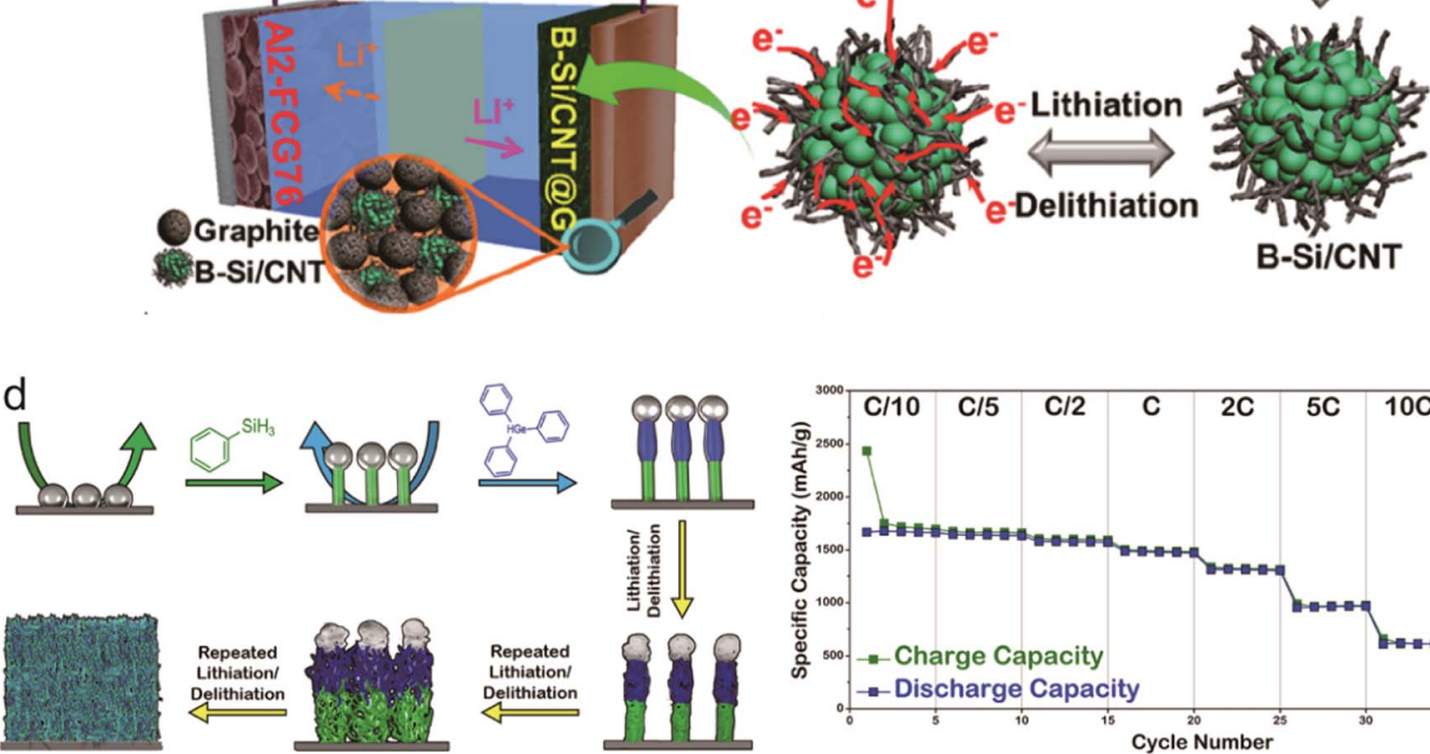

Repeated Lithiation/ Delithiation
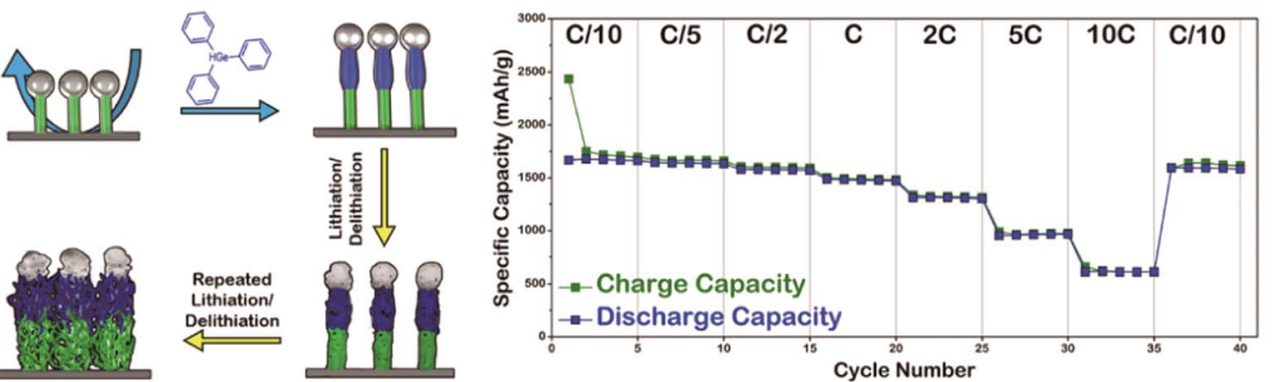

Fig. 4 Si-based composite materials as anodes: Si/graphite composites, (a-c) schematic of the procedures for the fabrication of SEAG. Reproduced with permission. ${ }^{56}$ Copyright (2017) Nature Publishing Group (a). Schematic gelation process and a picture as well as the model of the SiaCaCu composite. Reproduced with permission. ${ }^{57}$ Copyright (2019) American Chemical Society (b). Schematic illustration of the synthesis of B-Si/CNT. Reproduced with permission. ${ }^{58}$ Copyright (2019) American Chemical Society (c). Si-metal alloy, (d) overview of the synthetic protocol used to prepare $\mathrm{Sn}$-seeded $\mathrm{Si}-\mathrm{Ge}$ hNWs directly from current collectors. Charge and discharge capacities $\left(\mathrm{mA} \mathrm{h}^{-1}\right)$ demonstrated at different current rates. Reproduced with permission. ${ }^{29}$ Copyright (2018) American Chemical Society (d). 

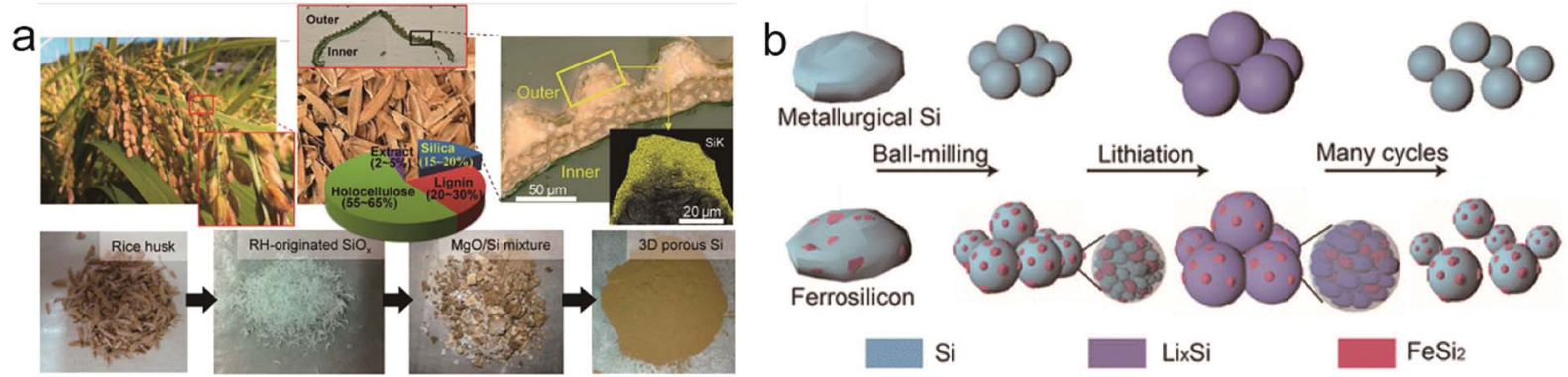

C

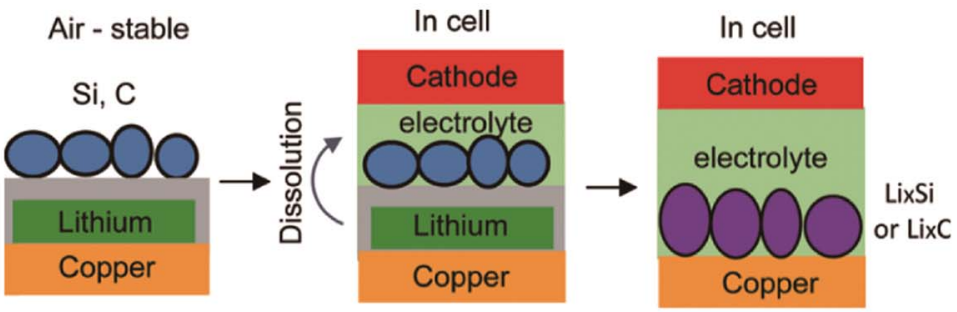

d

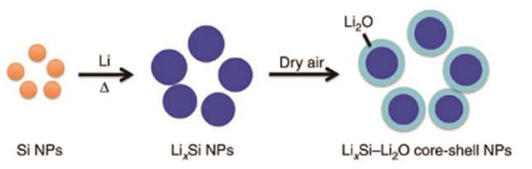

Protective layer (e.g. PMMA)

$\mathrm{Li}_{x}$ Si NPS $\mathrm{Li}_{x} \mathrm{Si}-\mathrm{Li} \mathrm{i}_{2} \mathrm{O}$ core-shell NPs
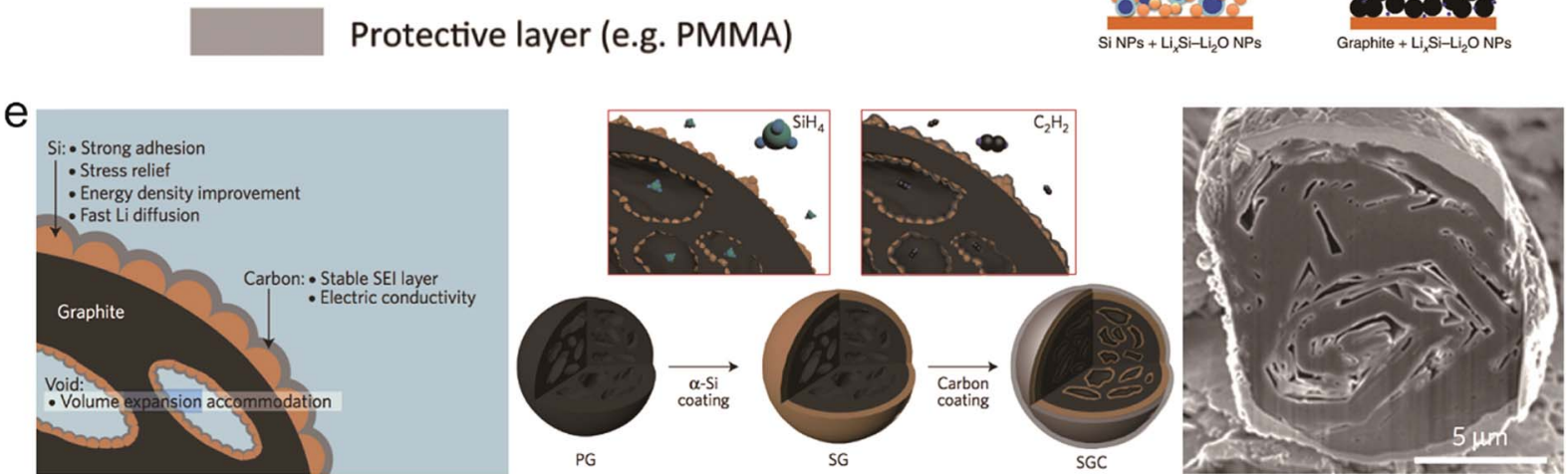

Fig. 5 Potential solutions for remaining problems of the Si anode: the high cost of the Si anode, (a and b) generation of 3D nanoporous Si from a rice plant. Reproduced with permission. ${ }^{61}$ Copyright (2013) National Academy of Sciences (a). Schematics of fabrication and electrochemical cycling of low grade silicon nanoparticles. Reproduced with permission. ${ }^{62}$ Copyright (2015) American Chemical Society (b). Relatively low initial $\mathrm{CE}$, (c-e) ambient-air stable prelithiation with polymer coating. Reproduced with permission. ${ }^{66}$ Copyright (2016) American Chemical Society (c). $\mathrm{Li}_{x} \mathrm{Si}$ nanoparticles. Reproduced with permission. ${ }^{67}$ Copyright (2014) Nature Publishing Group (d). Schematic, fabrication process, and crosssectional SEM image of silicon-nanolayer-embedded graphite. Reproduced with permission. ${ }^{69}$ Copyright (2016) Nature Publishing Group (e).

However, there are still some problems in making Si comparable with commercial graphite, which would need new holistic designs from materials, structures, binders and electrolytes.

\section{Li anode}

Li metal, with a theoretical specific capacity of $3860 \mathrm{~mA} \mathrm{~h} \mathrm{~g}{ }^{-1}$ and the lowest electrochemical potential of $-3.04 \mathrm{~V}$ ( $v s$. standard hydrogen electrode), is pursued as a promising anode for future Li-based batteries. In the 1970s, Li metal was first used as an anode for Li secondary cells by Stanley Whittingham. ${ }^{70}$ About ten years later, commercial $\mathrm{Li}$ metal batteries were emerging in the energy storage market with $\mathrm{MoS}_{2}$ as the cathode. ${ }^{71-73}$ However, many fire accidents caused public concern about the safety problems of Li metal batteries, and at last all the cells were recalled and withdrawn from the market. Many companies spent much time and funding to test Li metal cells to solve the safety issue, but eventually failed. Then subsequently, it's known to all that Sony launched a lithium-ion battery with carbonaceous anodes replacing Li metal, which has been widely used until now. But many researchers never gave up Li metal anodes because of their attractive high theoretical capacity (ten times higher than that of graphite). It's found that Li dendrite growth is the main reason of safety problems.

\subsection{Fundamental problems of the $\mathrm{Li}$ anode}

Because of its high electrochemical reactivity, Li metal can be easily corroded by organic electrolytes. ${ }^{74,75}$ Besides, like other alkali metal such as zinc, rough Li dendrites grow on the Li metal after cycling. ${ }^{76,77}$ To resolve the issue of the dendritic Li growth, we need to first figure out the mechanism of Li dendrite formation on the Li metal anode. Initially, the organic electrolyte reacts with $\mathrm{Li}$ to form a SEI layer on the $\mathrm{Li}$ anode. ${ }^{19,78} \mathrm{Li}$ ion deposition on the Li anode is uneven, because of the convection of electrolyte for Li diffusion and non-uniformity of the Li metal surface, leading to formation of an inhomogeneous and fragile SEI on Li. ${ }^{79-81}$ The inhomogeneous SEI also provides many different nucleation sites for subsequent $\mathrm{Li}$ ion deposition to aggravate the 
roughness of the surface until formation of Li dendrites. As a fragile SEI cannot hold the dendrite growth, the surface of the SEI would crack, exposing fresh Li metal to electrolyte during cycling, ultimately consuming the electrolyte (Fig. 6). Therefore, the continuous growth of dendritic Li will lead to many problems, limiting the cycling performance, resulting in cell short circuit and safety problems, and dead Li formation losing electrochemical contact. ${ }^{14}$ Various pathways have been explored to suppress Li dendrite growth, ${ }^{\mathbf{8 2 - 8 6}}$ including surface engineering on Li metal anodes, ${ }^{87-91}$ introducing a stable host for pre-storing $\mathrm{Li}^{\mathbf{9 2 - 9 7}}$ and electrolyte modification. ${ }^{\mathbf{9 8 - 1 0 1}}$

\subsection{Interfacial engineering to suppress $\mathrm{Li}$ dendrites}

To inhibit the formation of Li dendrites, it's feasible to design a stable interface or a protective layer between $\mathrm{Li}$ metal and electrolyte. In principle, the protective layer needs to possess some critical parameters: (1) mechanical and chemical stability to suppress the possible $\mathrm{Li}$ penetration; (2) good $\mathrm{Li}$ ion conductivity; (3) low electrical conductivity. To achieve the protective layer with good properties, various interfacial engineering methods have been proposed to improve the cycle performance of Li metal anodes. ${ }^{\mathbf{8 8 - 9 1 , 1 0 2 - 1 0 6}}$

Cui and co-workers proposed an interconnected amorphous hollow carbon layer coated on the $\mathrm{Li}$ anode through the flash evaporation method. The formed carbon layer had a good ion conductivity and high Young's modulus ( $200 \mathrm{GPa})$ enough to suppress Li dendrites. ${ }^{\mathbf{1 0 7}}$ Besides, the obtained hollow carbon layer was highly insulating due to large amounts of tetrahedral bonding. The insulating property enable that $\mathrm{Li}$ would be deposited underneath the carbon rather than on the top (Fig. 7a). The hollow carbon also provided space for Li deposition and can move up and down to adjust the availability and volume change during cycling. Using this protective layer, they achieved a high cycling $\mathrm{CE}$ of $\sim 99 \%$ at $1 \mathrm{~mA} \mathrm{~cm}^{-2} \mid 1 \mathrm{~mA} \mathrm{~h} \mathrm{~cm}^{-2}$ after 150 cycles without obvious Li dendrite formation. Besides the carbon layer, graphene or other two-dimensional materials have also been proved as good protective layers for preventing $\mathrm{Li}$ dendrite growth. ${ }^{\mathbf{1 0 8 , 1 0 9}}$

2D materials are effective in hindering Li dendrite growth due to their intrinsic high mechanical strength. Recently, Eunho Cha et al. demonstrated that $10 \mathrm{~nm}$ thick $\mathrm{MoS}_{2}$ as a protective layer on the Li metal anode can greatly improve the cycling stability. ${ }^{108}$ During the Li plating, Li atoms can intercalate into the atomically layered $\mathrm{MoS}_{2}$ structure, thus reducing the interfacial impedance and facilitating $\mathrm{Li}^{+}$ion transport (Fig. 7b). ${ }^{\mathbf{1 0 8}}$ The uniqueness of the $\mathrm{MoS}_{2}$ protective layer is that it experienced phase change (semiconductor to metallic trait) during cycling which is helpful in improving the interfacial contact. When paired with the carbon nanotube modified sulfide cathode, the full cell showed stability for 1200 cycles with an average CE of 98\% and high energy density up to $\sim 589 \mathrm{~W} \mathrm{~h} \mathrm{~kg}^{-1}$.

According to the requirements of the protective layer, the polymer is expected to modify the volume change of Li metal during cycling due to its flexibility. Zhu et al. demonstrated a porous poly(dimethylsiloxane) (PDMS) layer with nanopores to suppress Li dendrites. ${ }^{\mathbf{1 1 0}}$ The PDMS film is chemically inert, making it stable in the electrolyte. Because PDMS is not a good Li ion conductor, it's necessary to create some nanopores through acid treatment to provide the path for Li ion transport (Fig. 7c). The insulation of PDMS enabled Li deposition beneath the PDMS film. Under the protection of the obtained porous PDMS film with a thickness of $500 \mathrm{~nm}$ and $40-100 \mathrm{~nm}$ pore size, the Li anode presented stability for 200 cycles with CE reaching $94.5 \%$ in a common carbonate electrolyte. Some other polymers through modification were also utilized to protect the Li metal anode to suppress $\mathrm{Li}$ dendrite growth and accommodate the volumetric change during cycling.

The naturally formed SEI on the Li metal anode is fragile and unstable during cycling, so designing an artificial SEI to replace it is a promising strategy to stabilize the interface. Guo's group proposed an artificial $\mathrm{Li}_{3} \mathrm{PO}_{4} \mathrm{SEI}$ layer through an in situ reaction of polyphosphoric acid (PPA) with Li metal ${ }^{89}$ (Fig. 7d). Because of the high ion conductivity of the $\mathrm{Li}_{3} \mathrm{PO}_{4}$ layer, it enhanced the transport of $\mathrm{Li}^{+}$ions between the Li metal surface and electrolyte. Moreover, the $\mathrm{Li}_{3} \mathrm{PO}_{4}$ SEI layer separated the $\mathrm{Li}$ metal and electrolyte, avoiding unfavorable reactions. The obtained SEI layer remained uniform and possessed a high enough Young's modulus (10-11 GPa). Under the protection of the artificial $\mathrm{Li}_{3} \mathrm{PO}_{4} \mathrm{SEI}$, the $\mathrm{Li} \mid \mathrm{Li}_{3} \mathrm{PO}_{4}$ full cell presented lower polarization between the charge and discharge plateaus than that for the Li metal cell.

Nazar's group proposed an in situ formed metal alloy film through direct reduction of metal chlorides with $\mathrm{Li}$ as the protective layer to prevent $\mathrm{Li}$ dendrite growth. ${ }^{\mathbf{1 1 1}}$ The key point of the film is that the resultant metal in the first step reacted

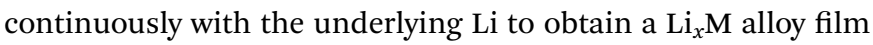
(M: In, Zn, Bi or As) while electronically insulating LiCl was formed as a by-product in the first step (Fig. 7e). The underlying $\mathrm{Li}_{x} \mathrm{M}$ film provided a fast pathway for $\mathrm{Li}$ ion transport and insulating $\mathrm{LiCl}$ impeded $\mathrm{Li}$ deposited directly on the top surface. With the alloy film modified Li metal as the symmetric electrode, it showed an extended cycling life of $1400 \mathrm{~h}$ at a current density of $2 \mathrm{~mA} \mathrm{~cm}{ }^{-2}$. When paired with the $\mathrm{Li}_{2} \mathrm{Ti}_{5} \mathrm{O}_{5}$

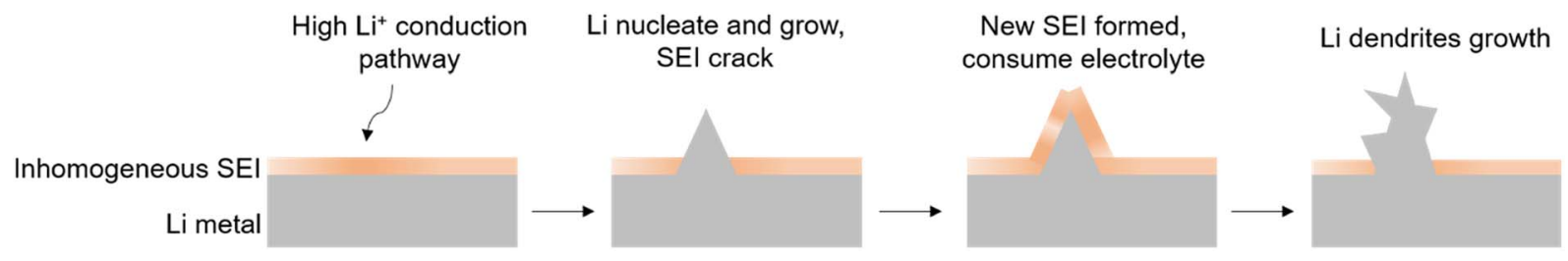

Fig. 6 The schematic of Li dendrite growth during cycling. 

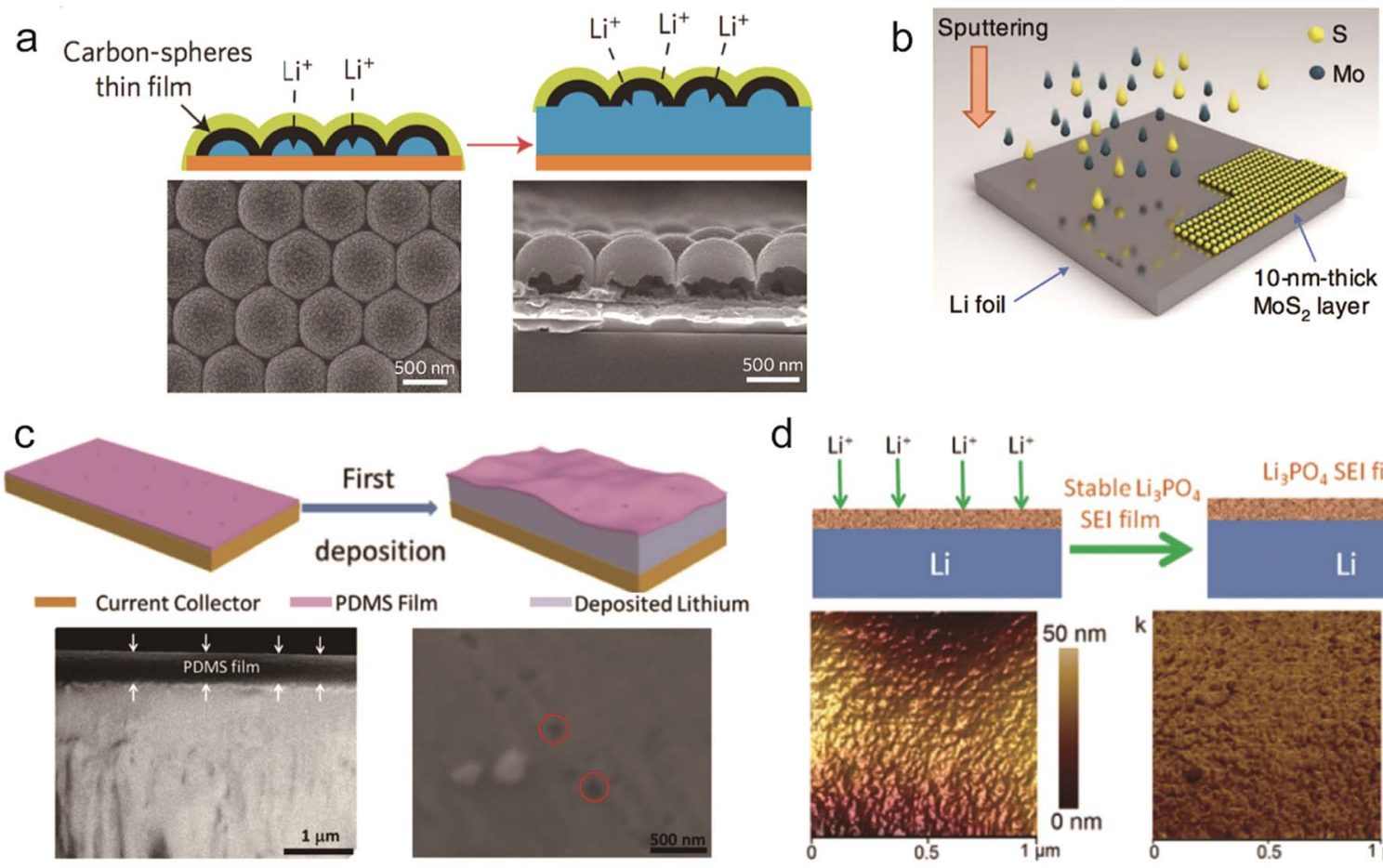

d

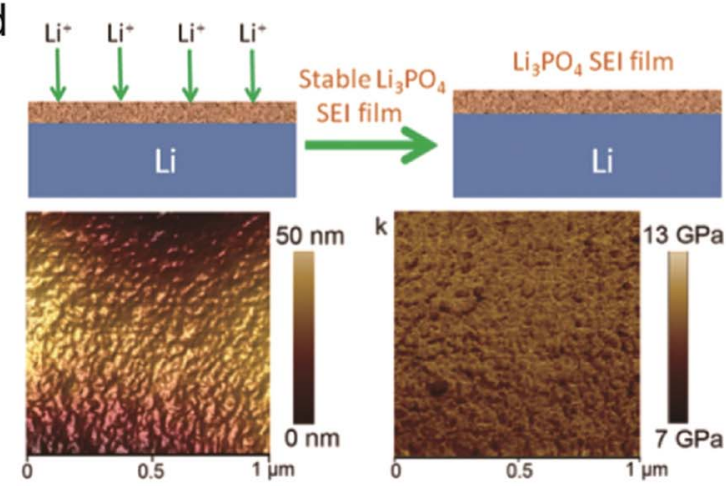

Alloy/LiCl
-protected Li
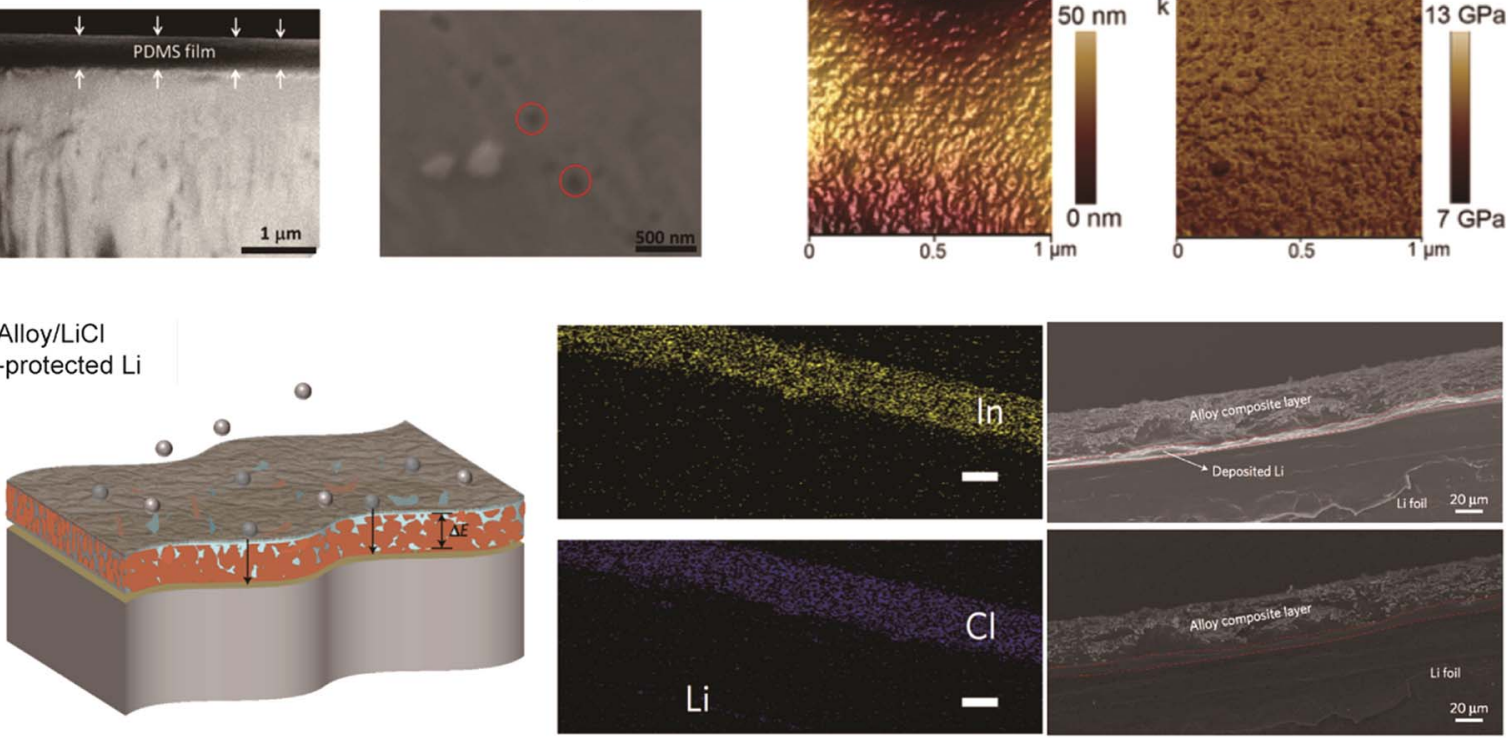

Fig. 7 Interfacial engineering to suppress Li dendrites. (a) Modifying the Cu substrate with a hollow carbon nanosphere layer creates a scaffold for stabilizing the SEI layer. Reproduced with permission. ${ }^{107}$ Copyright (2014) Nature Publishing Group. (b) Schematics illustrating the fabrication method for a MoS -coated Li anode via sputtering. Reproduced with permission. ${ }^{108}$ Copyright (2018) Nature Publishing Group. (c) Li deposition on the $\mathrm{Cu}$ foil coated with the PDMS thin film, with suppressed dendrite growth after many cycles. Reproduced with permission. ${ }^{110}$ Copyright (2016) Wiley $\mathrm{VCH}$. (d) $\mathrm{Li}_{3} \mathrm{PO}_{4}$-modified $\mathrm{Li}$ metal anodes, AFM image of the PPA-Li anode and corresponding Young's modulus mapping. Reproduced with permission. ${ }^{89}$ Copyright (2015) Wiley VCH. (e) Schematic depicting the function of the alloy-protected lithium foil, the EDS mapping of $\mathrm{In}$ and $\mathrm{Cl}$, and the cross-sectional image of a composite $\mathrm{Li}_{13} \mathrm{In}_{3} \mid \mathrm{Li}$ foil before Li plating. Reproduced with permission. ${ }^{111}$ Copyright (2017) Nature Publishing Group.

electrode, it presented a stable capacity for 1500 cycles without significant degradation.

\subsection{Host structure design for pre-storing $\mathrm{Li}$ to accommodate volume change}

The volumetric change of the $\mathrm{Li}$ anode is different from that of the $\mathrm{Si}$ anode because it experiences infinite volume change during Li plating/stripping. The infinite volume change always results in electrical contact loss and large ion conductivity resistance, degrading the cycle performance. ${ }^{97,112,113}$ Introducing stable hosts into the $\mathrm{Li}$ anode to minimize Li volumetric variation during cycling has been widely explored as a promising strategy. In principle, the development of host materials calls for some criteria as follows: (a) mechanical strength enough to hold the definite Li anode volume; (b) chemical and electrochemical stability during cycling; (c) large surface area to take up enough Li while possessing low weight.

Cui's group proposed various host designs for $\mathrm{Li}$ anodes to accommodate Li metal. ${ }^{114}$ Lin et al. found that rGO was a unique Li host material due to its good lithiophilicity. ${ }^{114}$ It can easily absorb molten $\mathrm{Li}$ inside the nanogaps and in the subsequent $\mathrm{Li}$ plating/stripping steps the thickness fluctuation of the $\mathrm{Li}$ composite anode was reduced to $\sim 20 \%$ (Fig. 8a). The high surface area of rGO also reduced the current density of the Li anode during cycling, while the Li content in the gaps reached $\sim 93 \%$ of the whole electrode. It exhibited a significantly low 

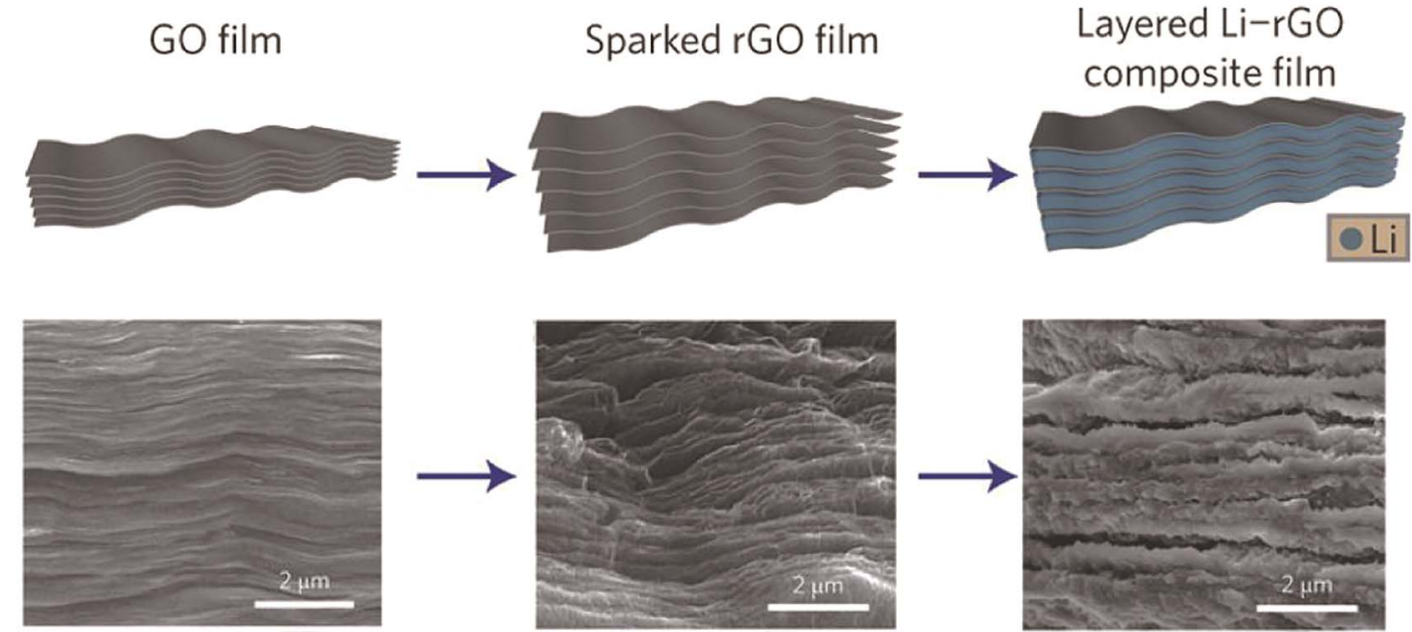

b

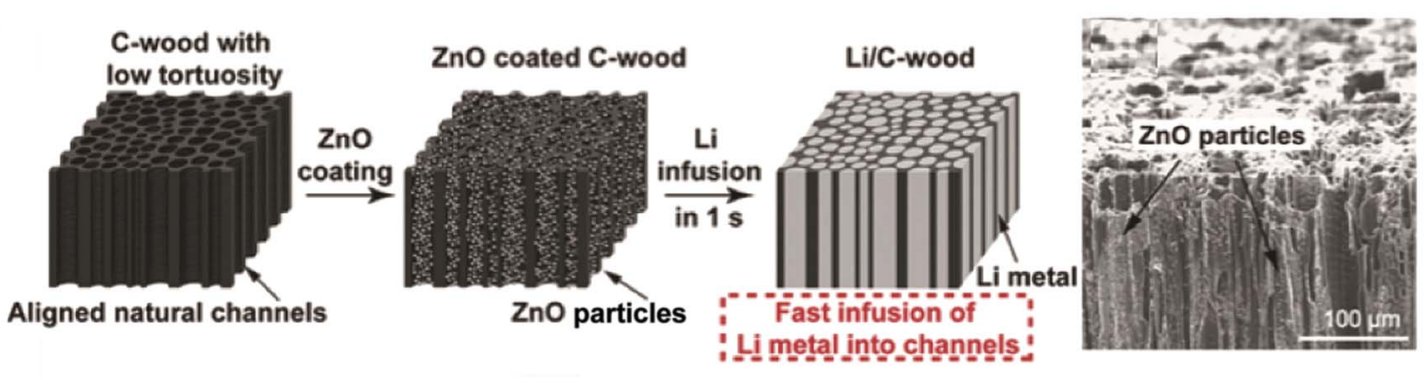

C
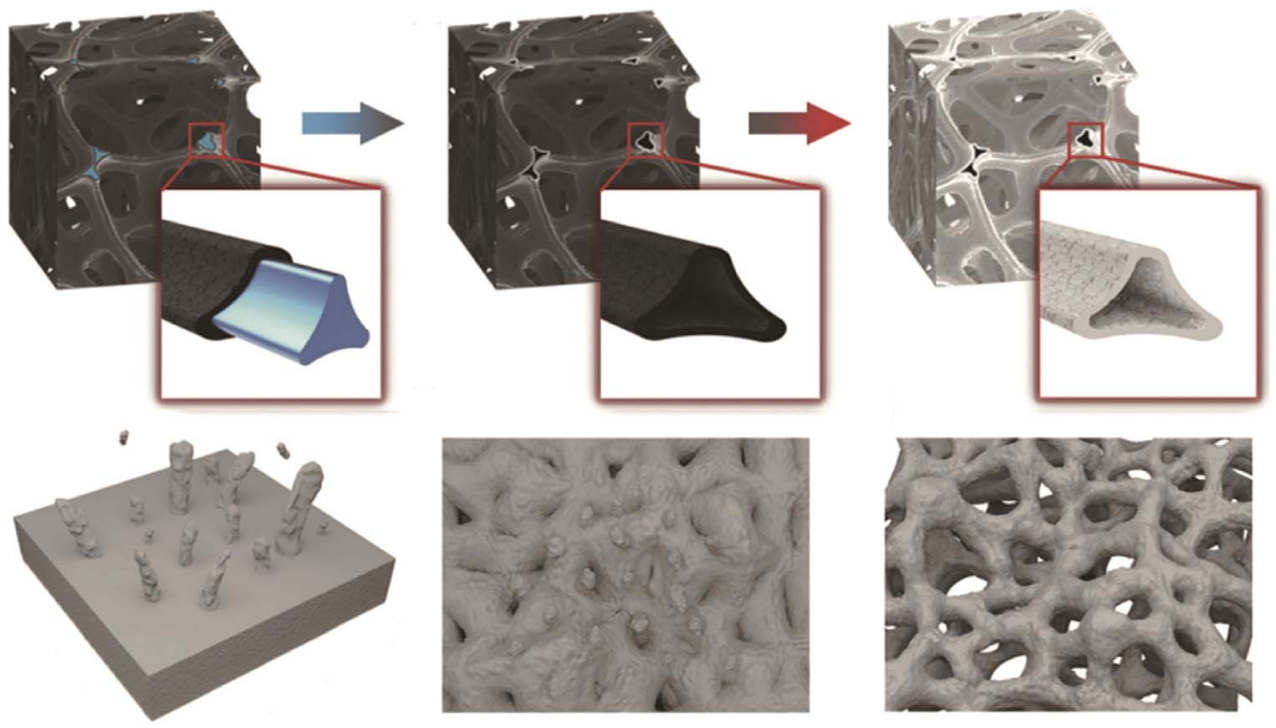

Fig. 8 Host structure design: (a) fabrication of a layered Li-rGO composite film and corresponding SEM images. Reproduced with permission. ${ }^{114}$ Copyright (2016) Nature Publishing Group. (b) Fabrication process of the Li/C-wood composite and corresponding SEM images. Reproduced with permission. ${ }^{115}$ Copyright (2016) National Academy of Sciences. (c) Schematic diagram of the fabrication procedure of Li foam. Reproduced with permission. ${ }^{116}$ Copyright (2018) Wiley VCH.

overpotential of $\sim 80 \mathrm{mV}$ at a current density of $3 \mathrm{~mA} \mathrm{~cm}{ }^{-2}$, suggesting low interfacial impedance. When paired with the $\mathrm{LiCoO}_{2}$ cathode, the full cell also showed much better cycling stability and rate performance.

$\mathrm{Hu}$ and co-workers used a carbonized wood with well-aligned channels as the host material for Li metal. ${ }^{115}$ Through ZnO coating, molten Li can easily infuse into the wood channels, and the obtained Li/C-wood confines the volume change during $\mathrm{Li}$ cycling (Fig. 8b). In view of the three-dimensional structure of Cwood, it also decreased the local current density of the Li anode. With the obtained Li/C-wood electrode prepared as a symmetric cell, it exhibited a low overpotential of $90 \mathrm{mV}$ and a stable cycling performance exceeding 150 cycles at a current density of $3 \mathrm{~mA} \mathrm{~cm}{ }^{-2}$. 
Some porous metal foams can also be used as host materials for pre-storing Li metal. Zhu's group proposed a highly porous Nickel (Ni) foam as a stable host for Li infusion inside due to the lithiophilicity of $\mathrm{Ni}^{\mathbf{1 1 6}}$ The porous structure and large surface area of the Ni foam provided enough space for Li metal and lowered the current density (Fig. 8c). Because of the stable structure of Ni foam, during Li plating/stripping the Li metal can be well confined in the Ni host, leading to a small overpotential of $\sim 25 \mathrm{mV}$ at $4 \mathrm{~mA} \mathrm{~cm}{ }^{-2}$. Because of its good charge mobility and uniform $\mathrm{Li}$ deposition, the $\mathrm{Li} / \mathrm{Ni}$ composite anode with the $\mathrm{LiFePO}_{4}$ cathode showed a high-rate performance of $138 \mathrm{~mA} \mathrm{~h} \mathrm{~g}^{-1}$ at $0.2 \mathrm{C}$.

\subsection{Liquid and solid electrolyte modification for improving Li metal anodes}

As reported before, all the organic solvents for electrolytes are thermodynamically unstable with $\mathrm{Li}$ metal. ${ }^{117}$ The reaction between electrolyte and Li metal results in not only low CE but also consumption of electrolyte. ${ }^{118,119}$ It's critical to modify the common organic electrolyte to obtain uniform Li deposition and improve the cycle stability of the Li anode. Zhang and coworkers demonstrated that using highly concentrated electrolytes consisting of ether solvents and salt Li bis(fluorosulfonyl) imide ( $\mathrm{LiFSI}$ or $\mathrm{LiN}\left(\mathrm{SO}_{2} \mathrm{~F}\right)_{2}$ ) can suppress the Li dendrite growth with high $\mathrm{CE}$ even at high current density ${ }^{\mathbf{1 0 0}}$ (Fig. 9a). The electrolyte salt LiFSI has a high ionic conductivity and $\mathrm{Li}^{+}$ transference number of $0.5-0.6$ because of its weak interaction between the $\mathrm{Li}^{+}$cation and $\mathrm{FSI}^{-}$anions, which is effective for reducing dendritic growth. Moreover, the authors used molecular dynamic (MD) simulations to uncover the underlying mechanism. They found that nearly all of the ions are present as contact ion pairs and aggregate solvate in $4 \mathrm{M}$ electrolyte, thereby improving the reductive stability of electrolyte while the increased $\mathrm{Li}$ ion concentration enables stable cycling during $\mathrm{Li}$ plating/stripping at high current density. With the highly concentrated electrolyte, the $\mathrm{Cu} \mid \mathrm{Li}$ cell showed a high $\mathrm{CE}$ of $>98 \%$ at $4 \mathrm{~mA} \mathrm{~cm}^{-2}$ after even 1000 cycles. Wang's group also did many studies on F-based electrolytes to improve Li metal anode performance. Fan et al. demonstrated that increasing the concentration of LiFSI to $10 \mathrm{M}$ in carbonate electrolyte can achieve excellent cycling performance of the Li anode. ${ }^{99}$ Highly concentrated LIFSI contributed to the high $\mathrm{F}$ content in the formed interphases between Li metal and electrolyte. The F-rich interphase can effectively suppress the Li dendrite growth during cycling according to the DFT calculations (Fig. 9c). When cycling in $1 \mathrm{M}$ and $10 \mathrm{M}$ LiFSI/DMC electrolyte, an obviously higher $\mathrm{CE}$ was shown for the $10 \mathrm{M}$ LiFSI additive reaching 99.3\% after 80 cycles (Fig. 9c). In the full cell test paired with the $\mathrm{LiNi}_{0.6} \mathrm{Mn}_{0.2} \mathrm{Co}_{0.2} \mathrm{O}_{2}$ cathode it still retained $\sim 86 \%$ of initial capacity after 100 cycles at a high voltage of $4.6 \mathrm{~V}$ and a high loading of $2.5 \mathrm{~m} \mathrm{~A} \mathrm{~h} \mathrm{~cm}^{-2}$.

Lu et al. proposed halogenated salt blends introduced in liquid electrolyte to achieve a stable long cycling of the $\mathrm{Li}$ metal anode. ${ }^{\mathbf{1 0 1}}$ Through the careful characterization of tension and impedance at the interface between electrolyte and $\mathrm{Li}$ metal, they attributed the stable electrochemical deposition of Li to the interfacial mobility of halogenated lithium salt. Joint density functional theoretical (JDFT) calculations also confirmed that the presence of lithium halides can improve the stability of Li plating/stripping. As an example, they introduced $30 \% \mathrm{LiF}$ into propylene carbonate (PC) and showed a stable cycling for more than $1800 \mathrm{~h}$, and no obvious Li dendrites were found (Fig. 9b).

Controlling the homogeneous Li ion flux can be beneficial for stable Li anode cycling even at high current density. Zhou and co-workers proposed adding porous metal-organic framework (MOF) species into the liquid electrolyte to modify the Li ion flux. ${ }^{120}$ It's known that the MOF host possesses angstrom-level pores which can impede the migration of large sized anions and just let Li ions go through (Fig. 9d). In the specific confined channels for Li ions, it can achieve a homogeneous $\mathrm{Li}$ flux and higher $\mathrm{Li}$ ion transference number. Consequently, at a high current density of $10 \mathrm{~mA} \mathrm{~cm}{ }^{-2}$ there are no obvious $\mathrm{Li}$ dendrites present in the Li metal surface after 1600 cycles.

The safety incidents (mainly fire breakout) of LIBs result from the inflammability of organic electrolytes. For the Li metal anode, the growth of $\mathrm{Li}$ dendrites during cycling makes the short circuit happen easier and results in security problems. So it's a promising strategy to replace liquid organic electrolytes with nonflammable solid state electrolytes to improve the safety of Li metal batteries. In the past decades, various solid electrolytes have been proposed and studied to improve the performance. ${ }^{\mathbf{1 2 1 , 1 2 2}}$ However, the poor interfacial contact between the Li metal anode and solid electrolyte, not like the good wettability of liquid electrolytes, leads to the formation of large interfacial impedance to reduce the performance of $\mathrm{Li}$ metal batteries. Hu's group showed that coating a thin aluminium oxide $\left(\mathrm{Al}_{2} \mathrm{O}_{3}\right)$ on a solid electrolyte through atomic layer deposition (ALD) can address the interfacial impedance between the Li metal and solid electrolyte. ${ }^{123} \mathrm{Li}$ metal has a good wettability with $\mathrm{Al}_{2} \mathrm{O}_{3}$ through reaction to form $\mathrm{Li}-\mathrm{Al}-\mathrm{O}$ (Fig. 9e), thereby negating the interfacial impedance. The formed $\mathrm{Li}-\mathrm{Al}-\mathrm{O}$ interface also possessed a high $\mathrm{Li}$ ion conductivity. With the $\mathrm{Al}_{2} \mathrm{O}_{3}$ modification, the interfacial impedance of garnet solid electrolyte $\mathrm{Li}_{7} \mathrm{La}_{2.75} \mathrm{Ca}_{0.25} \mathrm{Zr}_{1.75} \mathrm{Nb}_{0.25} \mathrm{O}_{12}$ (LLCZN) and Li metal decreased from $1710 \Omega \mathrm{cm}^{2}$ to $1 \Omega \mathrm{cm}^{2}$ at room temperature. Using the modified solid electrolyte in a full cell with a high voltage $\mathrm{Li}_{2} \mathrm{FeMn}_{3} \mathrm{O}_{8}$ (LFMO) cathode, it exhibited stable cycling for 50 cycles.

Apart from the three main strategies presented above, many researchers modified the $\mathrm{Li}$ metal anode cycle through designing current collector structures or strengthened the separator to avoid short circuit for Li metal batteries. However, for the realization of the practical application of the Li metal anode in the long term, designing a Li metal full cell remains a serious challenge, because of the volume variation at the electrode and battery level. For example, Li-LMO full cells are always assembled in the fully discharged state. During charging, significant volume expansion occurs, which would lead to enormous internal stress, causing safety problems and producing engineering challenges for battery packaging. To optimize the volumetric change of electrodes as well as 
a

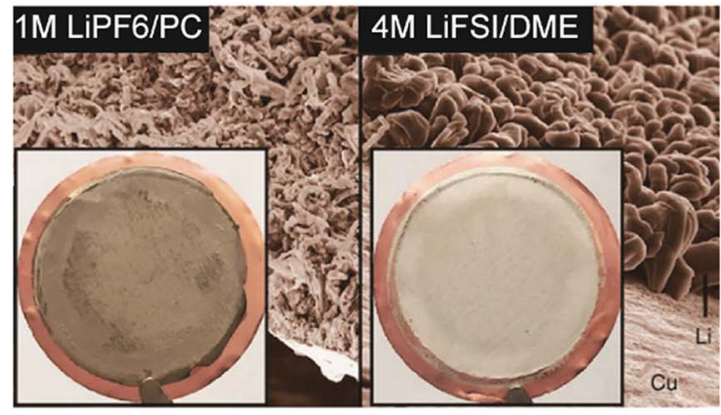

b
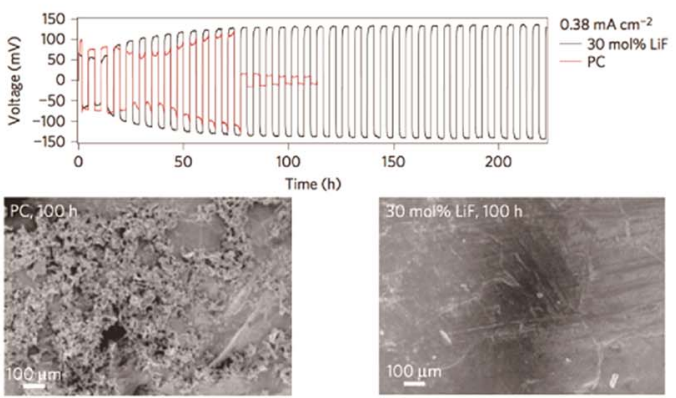
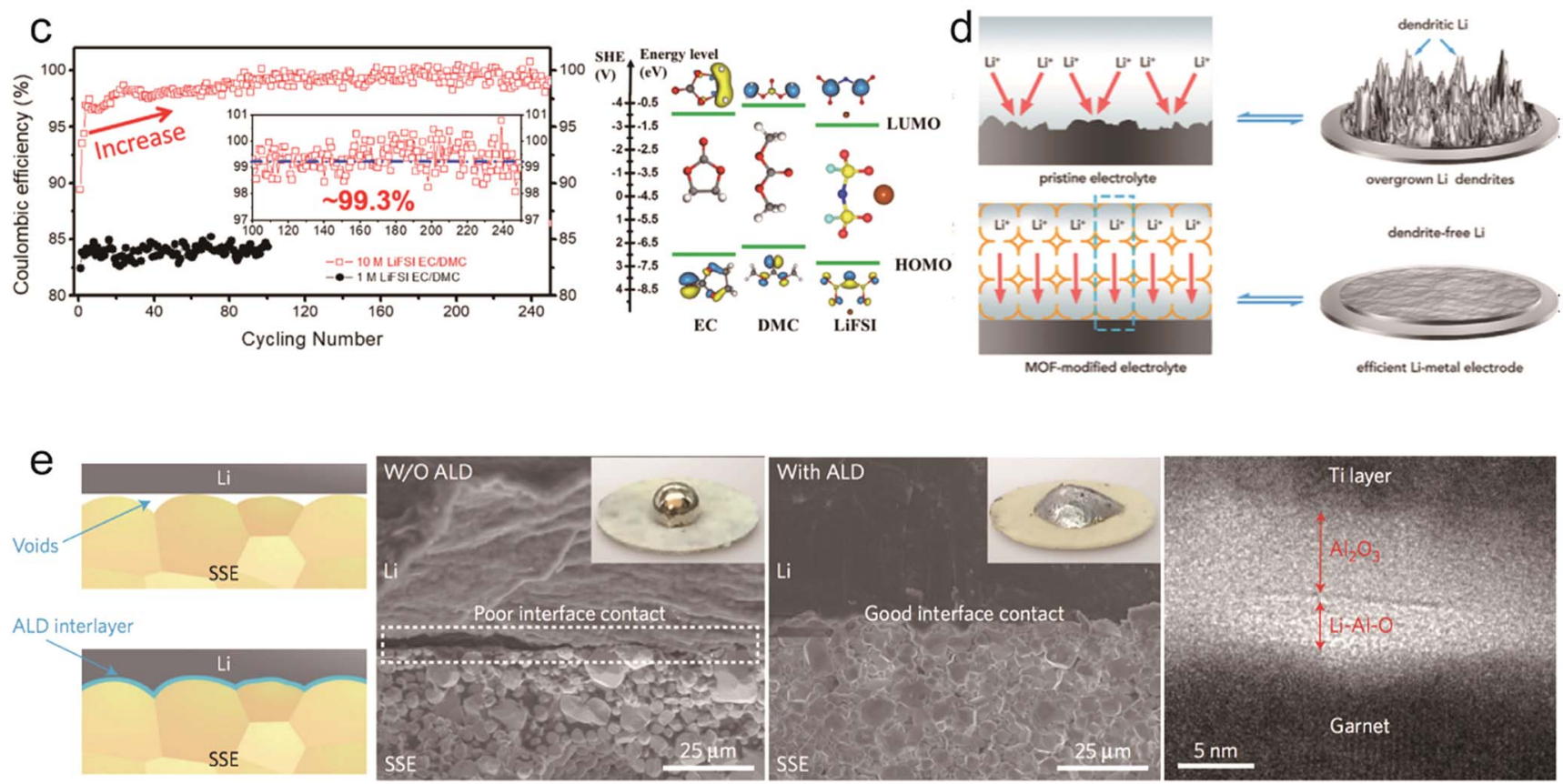

Fig. 9 Liquid and solid electrolyte modification for improving Li metal anodes: (a) SEM images of the morphologies of Li metal after plating on Cu substrates in different electrolytes. Reproduced with permission. ${ }^{100}$ Copyright (2015) Nature Publishing Group. (b) Voltage versus time for a symmetric lithium cell where each half-cycle lasts $3 \mathrm{~h}$ and the SEM analyses. Reproduced with permission. ${ }^{101}$ Copyright (2014) Nature Publishing Group. (c) Electrochemical Performance of Li-metal plating/stripping in $10 \mathrm{M} \mathrm{LiFSI-EC/DMC} \mathrm{(EC} \mathrm{:} \mathrm{DMC}=1: 1$ by volume) electrolyte and the LUMO and HOMO energy values of the solvents and the salt obtained by DFT simulations. Reproduced with permission. ${ }^{99}$ Copyright (2017) Elsevier Inc. (d) Schematic showing the Li-metal electrode with pristine electrolyte and the MOF-modified electrolyte. Reproduced with permission. ${ }^{120}$ Copyright (2018) Elsevier Inc. (e) Characterization of the garnet solid-state electrolyte/Li metal interface and the typical TEM crosssection image at the interface of the $\mathrm{ALD}-\mathrm{Al}_{2} \mathrm{O}_{3}$-coated garnet with a Ti protection layer. Reproduced with permission. ${ }^{123} \mathrm{Copyright}$ (2017) Nature Publishing Group.

designing electrodes with minimized volume change is an important direction towards the Li metal full cell. In addition, when assembling $\mathrm{Li}-\mathrm{S}$ and $\mathrm{Li}$-air full cells, the cathode species shuttled will transfer to the anode, which may change the Li deposition behavior and the components of the formed SEI. Therefore, interface engineering is necessary for minimizing the shuttling effect.

Because of the potential safety issues of the Li metal anode, integrating extra functions into a Li metal full cell to provide early warning of cell failure is highly desirable. For example, as it is well known that battery failure is typically accompanied by a temperature increase, it is worthy of exploring the integration of thermoresponsive materials into the battery system to detect battery failure.

\section{Advanced characterization techniques for Si and Li anodes}

In spite of the great progress obtained for Si and Li anodes, the underlying mechanism or what happened under the practical conditions still remained unclear. Diverse techniques have been utilized to explore the fundamental mechanisms of Si and Li anodes during cycling. ${ }^{68,124-127}$ For example, K. Ogata et al. used in situ NMR spectroscopy to reveal the phase transformations of the $\mathrm{Si}$ anode during lithiation/delithiation. ${ }^{124}$ They demonstrated Si nanowires as active materials grown on a carbon fiber support to provide a test battery system for ${ }^{7} \mathrm{Li}$ NMR spectroscopy (Fig. 10a). The experimental data and DFT calculations show that during over-lithiation of $\mathrm{c}-\mathrm{Li}_{3.75} \mathrm{Si}$ that 
a

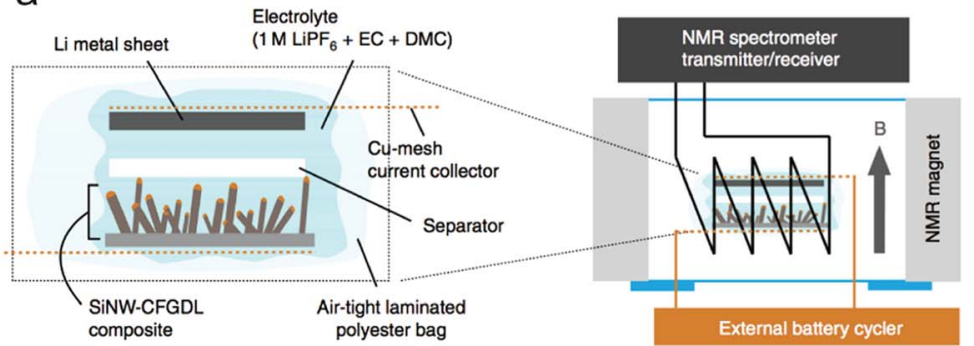

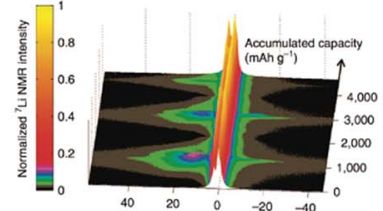

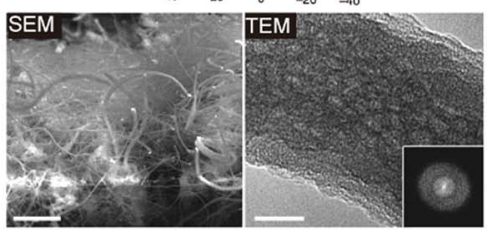

b
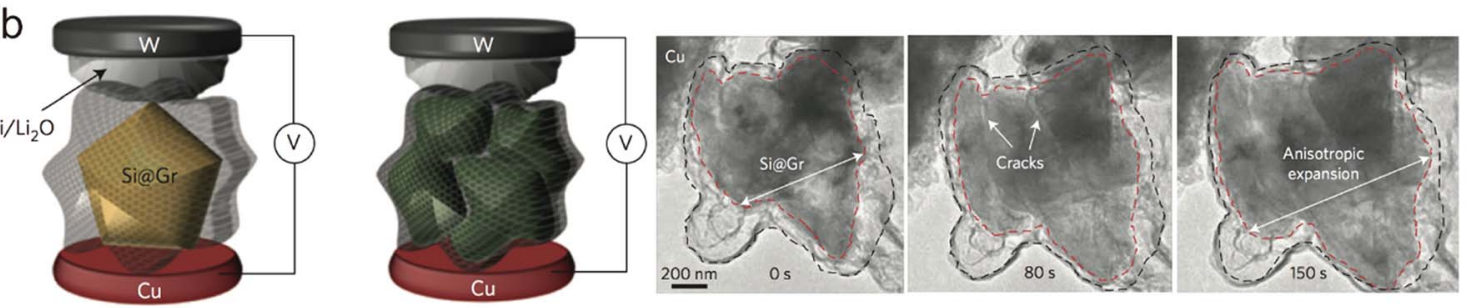

C
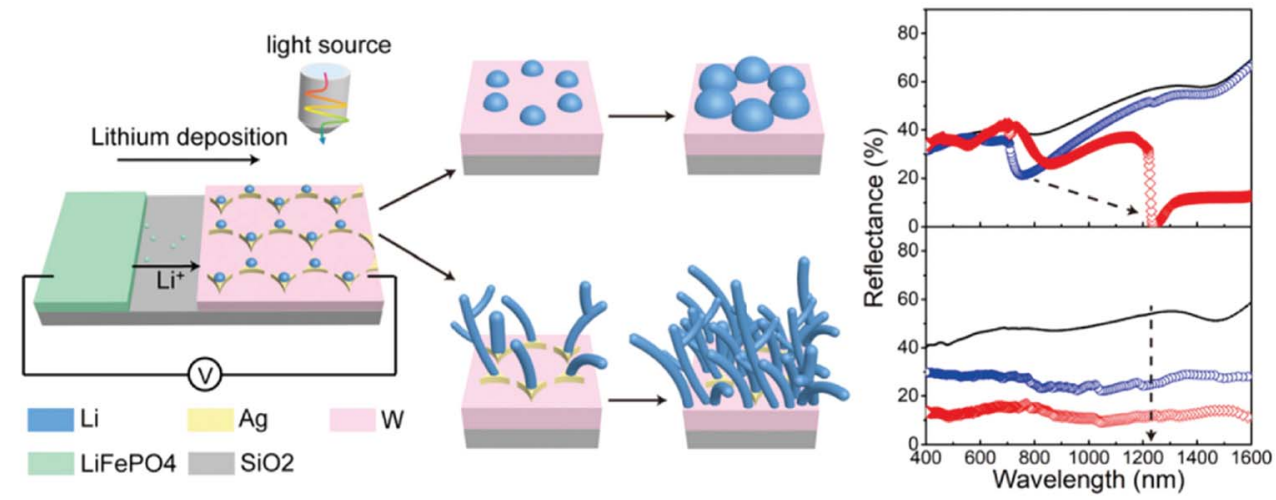

d
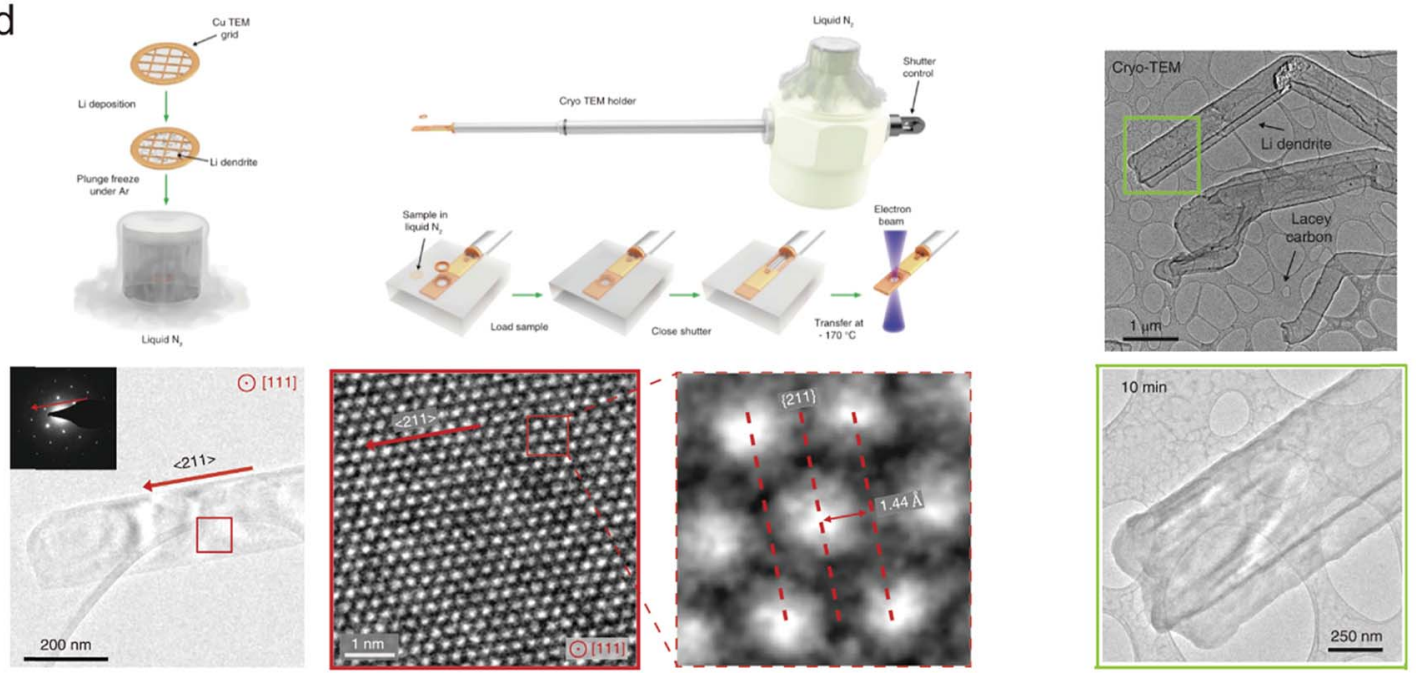

Fig. 10 Advanced characterization techniques for Si and Li anodes: (a) SEM images of as-grown SiNWs on CFGDL/colour-mapped in situ ${ }^{7} \mathrm{Li}$ NMR spectra of the SiNW-CFGDL composite/SEM and TEM images of cycled SiNWs. Reproduced with permission. ${ }^{124}$ Copyright (2014) Nature Publishing Group. (b) In situ TEM observation of graphene cage Si lithiation. Reproduced with permission. ${ }^{68}$ Copyright (2016) Nature Publishing Group. (c) In operando plasmonic monitoring of lithium morphological evolution in a battery. Reproduced with permission. ${ }^{125}$ Copyright (2018) National Academy of Sciences. (d) Preserving and stabilizing Li metal by cryo-EM and Atomic-resolution TEM of Li metal dendrites. Reproduced with permission. ${ }^{126}$ Copyright (2017) Science. 
occurs below $50 \mathrm{mV}$, small clusters can form within the $\mathrm{Li}_{3.75} \mathrm{Si}$ phase during charge. This also illustrated the close connection between the phases formed and the rate of lithiation. Besides, to observe the morphological evolution clearly, in situ TEM has been widely used for probing Si anodes during cycling. Cui's group studied the volume change of Si anodes during cycling relying on in situ TEM, which provided direct proof for evaluating designed structures ${ }^{68}$ (Fig. 10b). However, as the practical liquid electrolyte conditions can hardly be realized in TEM, surface chemistry change such as SEI was limited.

It's difficult to monitor the electrochemical evolution of $\mathrm{Li}$ metal in operando during cycling without destruction because of its high chemical reactivity and weak atomic bonding. Recently, Zhu's group demonstrated that they could in operando identify the morphology evolution of the Li metal anode during cycling through nondestructive optical spectroscopies based on the mechanism of plasmonics. ${ }^{\mathbf{1 2 5}}$ They established the relationship between the spectroscopic features and the morphology of deposited Li numerically and experimentally. Ordered silver electrodes on a tungsten film are finely designed for selective deposition of $\mathrm{Li}$ metal while the $\mathrm{LiFePO}_{4}$ cathode provides the Li ion (Fig. 10c). During deposition, Li metal tends to selectively nucleate on silver seeds more regularly to form periodic lithium particles with gradual size increases over deposition time under low current density; when increasing the current density, undesirable formation of lithium dendrites is commonly triggered. These two different morphologies correspond to different spectroscopic features, and thus they can detect the formation of Li dendrites during cycling (Fig. 10c). This provides a promising strategy to investigate Li metal anode behavior under various working conditions.

Because of the high reactivity and sensitivity of Li metal, it still remains a challenge to observe the detailed nanostructures and crystallography of $\mathrm{Li}$ and the SEI formed during cycling at the nanoscale. A high electron dose can easily damage the sample. Cui and co-workers first used cryo-electron microscopy techniques to characterize the Li metal anode and its SEI on the surface $^{126}$ (Fig. 10d). Through flash-freezing the copper TEM grid covered with Li deposition in liquid nitrogen to avoid the influences of air and the electron beam, the real electrochemical state of Li dendrites and the SEI after cycling can be probed without causing any damage and the atomic resolution can reach up to $0.7 \AA$.

We expect that combining these new advanced characterization techniques with detailed simulations, the holistic underlying mechanism and dynamic behavior of $\mathrm{Si}$ and $\mathrm{Li}$ anodes during cycling would be uncovered.

\section{Conclusions and outlook}

$\mathrm{Si}$ and $\mathrm{Li}$ anodes have shown great promise as next generation lithium battery anodes due to their high capacity, while major problems such as large volume changes during cycling limit their applications. In this review, we have summarized the recent progress in $\mathrm{Si}$ and $\mathrm{Li}$ anodes as well as the discussion of the principles for design to improve the performance. We also took some typical examples to illustrate these principles.
Although progress has been made, the as-developed strategies remain far from the requirements of commercialization. For Si anodes, the initial $\mathrm{CE}$ at least reaching $90 \%$ and the average $\mathrm{CE}$ of $>99.8 \%$ in the subsequent cycles are favorable to minimize the consumption of $\mathrm{Li}$ in the practical cell. However, the present $\mathrm{Si}$ anodes still cannot meet this demand yet. Besides, to alleviate the large volume change of $\mathrm{Si}$ anodes during cycling, the excess space designed for volume expansion always reduces the specific volume capacity. This calls for new advanced full cell designs. For Li anodes, while host design, surface engineering and electrolyte modification can relieve the problem of Li dendrite growth, stable long cycle performance is limited in practical full cells. Solid electrolyte is a promising choice to resolve most problems, but its low ion conductivity and poor interfacial contact need much improvement.

We think future practical $\mathrm{Si}$ and $\mathrm{Li}$ anodes need to combine several possible solutions mentioned above or need design of brand-new structures, which involves complicated system engineering. In the meantime, with the help of advanced characterization tools and simulation methods, the underlying fundamental mechanism in $\mathrm{Si}$ and $\mathrm{Li}$ anodes can be uncovered, which will provide the guidance for the design. The wideapplication of higher energy lithium-based rechargeable batteries with $\mathrm{Si}$ and $\mathrm{Li}$ as anodes is the critical enabler for the transformation towards an electrified future, and it is now on its way.

\section{Conflicts of interest}

There are no conflicts to declare.

\section{Acknowledgements}

We acknowledge the micro-fabrication center of National Laboratory of Solid State Microstructures (NLSSM) for technique support and Jiangsu Donghai Silicon Industry Science and Technology Innovation Center. This work is jointly supported by the National Key Research and Development Program of China (No. 2017YFA0205700) and the State Key Program for Basic Research of China (No. 2015CB659300), the National Natural Science Foundation of China (No. 21805132, 11574143, 11874211, 11621091, and 61735008), the Natural Science Foundation of Jiangsu Province (No. BK20180341) and the Fundamental Research Funds for the Central Universities (No. 021314380135 and 021314380128 ).

\section{References}

1 M. Armand and J. M. Tarascon, Nature, 2008, 451, 652.

2 K. Xu, Chem. Rev., 2004, 104, 4303-4418.

3 B. Kang and G. Ceder, Nature, 2009, 458, 190.

4 A. S. Aricò, P. Bruce, B. Scrosati, J.-M. Tarascon and W. van Schalkwijk, Nat. Mater., 2005, 4, 366.

5 J. M. Tarascon and M. Armand, Nature, 2001, 414, 359.

6 Z. Lin, T. Liu, X. Ai and C. Liang, Nat. Commun., 2018, 9, 5262.

7 P. G. Bruce, S. A. Freunberger, L. J. Hardwick and J.-M. Tarascon, Nat. Mater., 2011, 11, 19. 
8 H. Gao, L. Xiao, I. Plümel, G.-L. Xu, Y. Ren, X. Zuo, Y. Liu, C. Schulz, H. Wiggers, K. Amine and Z. Chen, Nano Lett., 2017, 17, 1512-1519.

9 A. Casimir, H. Zhang, O. Ogoke, J. C. Amine, J. Lu and G. Wu, Nano Energy, 2016, 27, 359-376.

10 S. Tardif, E. Pavlenko, L. Quazuguel, M. Boniface, M. Maréchal, J.-S. Micha, L. Gonon, V. Mareau, G. Gebel, P. Bayle-Guillemaud, F. Rieutord and S. Lyonnard, ACS Nano, 2017, 11, 11306-11316.

11 J. Lang, B. Ding, T. Zhu, H. Su, H. Luo, L. Qi, K. Liu, K. Wang, N. Hussain, C. Zhao, X. Li, H. Gao and H. Wu, Adv. Mater., 2016, 28, 10236-10243.

12 H. Wang, M. Wu, X. Lei, Z. Tian, B. Xu, K. Huang and C. Ouyang, Nano Energy, 2018, 49, 67-76.

13 K. Ogata, S. Jeon, D. S. Ko, I. S. Jung, J. H. Kim, K. Ito, Y. Kubo, K. Takei, S. Saito, Y. H. Cho, H. Park, J. Jang, H. G. Kim, J. H. Kim, Y. S. Kim, W. Choi, M. Koh, K. Uosaki, S. G. Doo, Y. Hwang and S. Han, Nat. Commun., 2018, 9, 479.

14 X.-B. Cheng, R. Zhang, C.-Z. Zhao and Q. Zhang, Chem. Rev., 2017, 117, 10403-10473.

15 X. Shen, H. Liu, X.-B. Cheng, C. Yan and J.-Q. Huang, Energy Storage Materials, 2018, 12, 161-175.

16 P. Zou, Y. Wang, S.-W. Chiang, X. Wang, F. Kang and C. Yang, Nat. Commun., 2018, 9, 464.

17 F. Wu, Y.-X. Yuan, X.-B. Cheng, Y. Bai, Y. Li, C. Wu and Q. Zhang, Energy Storage Materials, 2018, 15, 148-170.

18 L. Wang, Z. Zhou, X. Yan, F. Hou, L. Wen, W. Luo, J. Liang and S. X. Dou, Energy Storage Materials, 2018, 14, 22-48.

19 Y. Guo, H. Li and T. Zhai, Adv. Mater., 2017, 29, 1700007.

20 J. Lang, L. Qi, Y. Luo and H. Wu, Energy Storage Materials, 2017, 7, 115-129.

21 P. Li, G. Zhao, X. Zheng, X. Xu, C. Yao, W. Sun and S. X. Dou, Energy Storage Materials, 2018, 15, 422-446.

22 M. Ashuri, Q. He and L. L. Shaw, Nanoscale, 2016, 8, 74-103.

23 A. M. Haregewoin, A. S. Wotango and B.-J. Hwang, Energy Environ. Sci., 2016, 9, 1955-1988.

24 N. Fukata, T. Subramani, W. Jevasuwan, M. Dutta and Y. Bando, Small, 2017, 13, 1701713.

25 K. Feng, M. Li, W. Liu, A. G. Kashkooli, X. Xiao, M. Cai and Z. Chen, Small, 2018, 14, 1702737.

26 M. T. McDowell, I. Ryu, S. W. Lee, C. Wang, W. D. Nix and Y. Cui, Adv. Mater., 2012, 24, 6034-6041.

27 I. Ryu, J. W. Choi, Y. Cui and W. D. Nix, J. Mech. Phys. Solids, 2011, 59, 1717-1730.

28 T. Ma, X. Yu, H. Li, W. Zhang, X. Cheng, W. Zhu and X. Qiu, Nano Lett., 2017, 17, 3959-3964.

29 K. Stokes, G. Flynn, H. Geaney, G. Bree and K. M. Ryan, Nano Lett., 2018, 18, 5569-5575.

30 R. Mukherjee, R. Krishnan, T.-M. Lu and N. Koratkar, Nano Energy, 2012, 1, 518-533.

31 J. Ryu, D. Hong, S. Choi and S. Park, ACS Nano, 2016, 10, 2843-2851.

32 Y.-C. Zhang, Y. You, S. Xin, Y.-X. Yin, J. Zhang, P. Wang, X.-s. Zheng, F.-F. Cao and Y.-G. Guo, Nano Energy, 2016, 25, 120-127.
33 D. Vrankovic, M. Graczyk-Zajac, C. Kalcher, J. Rohrer, M. Becker, C. Stabler, G. Trykowski, K. Albe and R. Riedel, ACS Nano, 2017, 11, 11409-11416.

34 H. Shang, Z. Zuo, L. Yu, F. Wang, F. He and Y. Li, Adv. Mater., 2018, 30, 1801459.

35 H. Jia, J. Zheng, J. Song, L. Luo, R. Yi, L. Estevez, W. Zhao, R. Patel, X. Li and J.-G. Zhang, Nano Energy, 2018, 50, 589-597.

36 Y. Liu, Z. Tai, T. Zhou, V. Sencadas, J. Zhang, L. Zhang, K. Konstantinov, Z. Guo and H. K. Liu, Adv. Mater., 2017, 29, 1703028.

37 H. Wu, G. Zheng, N. Liu, T. J. Carney, Y. Yang and Y. Cui, Nano Lett., 2012, 12, 904-909.

38 H. Jia, P. Gao, J. Yang, J. Wang, Y. Nuli and Z. Yang, Adv. Energy Mater., 2011, 1, 1036-1039.

39 H. Ma, F. Cheng, J.-Y. Chen, J.-Z. Zhao, C.-S. Li, Z.-L. Tao and J. Liang, Adv. Mater., 2007, 19, 4067-4070.

40 Z. Zhang, Y. Wang, W. Ren, Q. Tan, Y. Chen, H. Li, Z. Zhong and F. Su, Angew. Chem., 2014, 126, 5265-5269.

41 N. Liu, Z. Lu, J. Zhao, M. T. McDowell, H.-W. Lee, W. Zhao and Y. Cui, Nat. Nanotechnol., 2014, 9, 187.

42 X. H. Liu, L. Zhong, S. Huang, S. X. Mao, T. Zhu and J. Y. Huang, ACS Nano, 2012, 6, 1522-1531.

43 Y. Sun, N. Liu and Y. Cui, Nat. Energy, 2016, 1, 16071.

44 C. K. Chan, H. Peng, G. Liu, K. McIlwrath, X. F. Zhang, R. A. Huggins and Y. Cui, Nat. Nanotechnol., 2007, 3, 31.

45 A. Magasinski, P. Dixon, B. Hertzberg, A. Kvit, J. Ayala and G. Yushin, Nat. Mater., 2010, 9, 353.

46 N. Liu, H. Wu, M. T. McDowell, Y. Yao, C. Wang and Y. Cui, Nano Lett., 2012, 12, 3315-3321.

47 Y. Horowitz, H.-L. Han, F. A. Soto, W. T. Ralston, P. B. Balbuena and G. A. Somorjai, Nano Lett., 2018, 18, 1145-1151.

48 A. Schiele, B. Breitung, T. Hatsukade, B. B. Berkes, P. Hartmann, J. Janek and T. Brezesinski, ACS Energy Lett., 2017, 2, 2228-2233.

49 Y. Okuno, K. Ushirogata, K. Sodeyama and Y. Tateyama, Phys. Chem. Chem. Phys., 2016, 18, 8643-8653.

50 H. Chen, M. Ling, L. Hencz, H. Y. Ling, G. Li, Z. Lin, G. Liu and S. Zhang, Chem. Rev., 2018, 118, 8936-8982.

51 S. Kim, Y. K. Jeong, Y. Wang, H. Lee and J. W. Choi, $A d v$. Mater., 2018, 30, 1707594.

52 S. Guo, H. Li, Y. Li, Y. Han, K. Chen, G. Xu, Y. Zhu and X. Hu, Adv. Energy Mater., 2018, 8, 1800434.

53 D. Liu, Y. Zhao, R. Tan, L.-L. Tian, Y. Liu, H. Chen and F. Pan, Nano Energy, 2017, 36, 206-212.

54 S. Choi, T.-w. Kwon, A. Coskun and J. W. Choi, Science, 2017, 357, 279-283.

55 C. Wang, H. Wu, Z. Chen, M. T. McDowell, Y. Cui and Z. Bao, Nat. Chem., 2013, 5, 1042.

56 N. Kim, S. Chae, J. Ma, M. Ko and J. Cho, Nat. Commun., 2017, 8, 812.

57 H. Zhang, P. Zong, M. Chen, H. Jin, Y. Bai, S. Li, F. Ma, H. Xu and K. Lian, ACS Nano, 2019, 13, 3054-3062.

58 P. Li, J.-Y. Hwang and Y.-K. Sun, ACS Nano, 2019, 13, 26242633. 
59 Y. Jin, S. Li, A. Kushima, X. Zheng, Y. Sun, J. Xie, J. Sun, W. Xue, G. Zhou, J. Wu, F. Shi, R. Zhang, Z. Zhu, K. So, Y. Cui and J. Li, Energy Environ. Sci., 2017, 10, 580-592.

60 J. Wang, L. Liao, Y. Li, J. Zhao, F. Shi, K. Yan, A. Pei, G. Chen, G. Li, Z. Lu and Y. Cui, Nano Lett., 2018, 18, 7060-7065.

61 D. S. Jung, M.-H. Ryou, Y. J. Sung, S. B. Park and J. W. Choi, Proc. Natl. Acad. Sci. U. S. A., 2013, 110, 12229-12234.

62 B. Zhu, Y. Jin, Y. Tan, L. Zong, Y. Hu, L. Chen, Y. Chen, Q. Zhang and J. Zhu, Nano Lett., 2015, 15, 5750-5754.

63 L. Zong, B. Zhu, Z. Lu, Y. Tan, Y. Jin, N. Liu, Y. Hu, S. Gu, J. Zhu and Y. Cui, Proc. Natl. Acad. Sci. U. S. A., 2015, 112, 13473-13477.

64 Y. Jin, S. Zhang, B. Zhu, Y. Tan, X. Hu, L. Zong and J. Zhu, Nano Lett., 2015, 15, 7742-7747.

65 L. Zong, Y. Jin, C. Liu, B. Zhu, X. Hu, Z. Lu and J. Zhu, Nano Lett., 2016, 16, 7210-7215.

66 Z. Cao, P. Xu, H. Zhai, S. Du, J. Mandal, M. Dontigny, K. Zaghib and Y. Yang, Nano Lett., 2016, 16, 7235-7240.

67 J. Zhao, Z. Lu, N. Liu, H.-W. Lee, M. T. McDowell and Y. Cui, Nat. Commun., 2014, 5, 5088.

68 Y. Li, K. Yan, H.-W. Lee, Z. Lu, N. Liu and Y. Cui, Nat. Energy, 2016, 1, 15029.

69 M. Ko, S. Chae, J. Ma, N. Kim, H.-W. Lee, Y. Cui and J. Cho, Nat. Energy, 2016, 1, 16113.

70 M. S. Whittingham, Chem. Rev., 2004, 104, 4271-4302.

71 C. Feng, J. Ma, H. Li, R. Zeng, Z. Guo and H. Liu, Mater. Res. Bull., 2009, 44, 1811-1815.

72 J. Xiao, D. Choi, L. Cosimbescu, P. Koech, J. Liu and J. P. Lemmon, Chem. Mater., 2010, 22, 4522-4524.

73 K. Chang and W. Chen, ACS Nano, 2011, 5, 4720-4728.

74 A. Kushima, K. P. So, C. Su, P. Bai, N. Kuriyama, T. Maebashi, Y. Fujiwara, M. Z. Bazant and J. Li, Nano Energy, 2017, 32, 271-279.

75 K. N. Wood, M. Noked and N. P. Dasgupta, ACS Energy Lett., 2017, 2, 664-672.

76 P. Albertus, S. Babinec, S. Litzelman and A. Newman, Nat. Energy, 2018, 3, 16-21.

77 M. J. Zachman, Z. Tu, S. Choudhury, L. A. Archer and L. F. Kourkoutis, Nature, 2018, 560, 345-349.

78 D. Lin, Y. Liu and Y. Cui, Nat. Nanotechnol., 2017, 12, 194. 79 G. M. A. Girard, M. Hilder, N. Dupre, D. Guyomard, D. Nucciarone, K. Whitbread, S. Zavorine, M. Moser, M. Forsyth, D. R. MacFarlane and P. C. Howlett, ACS Appl. Mater. Interfaces, 2018, 10, 6719-6729.

80 X.-B. Cheng, C. Yan, X.-Q. Zhang, H. Liu and Q. Zhang, ACS Energy Lett., 2018, 3, 1564-1570.

81 S. Jiao, J. Zheng, Q. Li, X. Li, M. H. Engelhard, R. Cao, J.-G. Zhang and W. Xu, Joule, 2018, 2, 110-124.

82 J. Lang, Y. Long, J. Qu, X. Luo, H. Wei, K. Huang, H. Zhang, L. Qi, Q. Zhang, Z. Li and H. Wu, Energy Storage Materials, 2019, 16, 85-90.

83 C. Li, J. Wei, P. Li, W. Tang, W. Feng, J. Liu, Y. Wang and Y. Xia, Sci. Bull., 2019, 64, 478-484.

84 H. Qiu, T. Tang, M. Asif, X. Huang and Y. Hou, Adv. Funct. Mater., 2019, 29, 1808468.
85 P. Shi, T. Li, R. Zhang, X. Shen, X.-B. Cheng, R. Xu, J.-Q. Huang, X.-R. Chen, H. Liu and Q. Zhang, Adv. Mater., 2019, 31, 1807131.

86 F. Liu, R. Xu, Z. Hu, S. Ye, S. Zeng, Y. Yao, S. Li and Y. Yu, Small, 2019, 15, 1803734.

87 H. Yang, C. Guo, A. Naveed, J. Lei, J. Yang, Y. Nuli and J. Wang, Energy Storage Materials, 2018, 14, 199-221.

88 R. Xu, X.-Q. Zhang, X.-B. Cheng, H.-J. Peng, C.-Z. Zhao, C. Yan and J.-Q. Huang, Adv. Funct. Mater., 2018, 28, 1705838.

89 N.-W. Li, Y.-X. Yin, C.-P. Yang and Y.-G. Guo, Adv. Mater., 2016, 28, 1853-1858.

90 J. Xie, L. Liao, Y. Gong, Y. Li, F. Shi, A. Pei, J. Sun, R. Zhang, B. Kong, R. Subbaraman, J. Christensen and Y. Cui, Sci. Adv., 2017, 3, eaao3170.

91 J. Xie, J. Wang, H. R. Lee, K. Yan, Y. Li, F. Shi, W. Huang, A. Pei, G. Chen, R. Subbaraman, J. Christensen and Y. Cui, Sci. Adv., 2018, 4, eaat5168.

92 C. Jin, O. Sheng, J. Luo, H. Yuan, C. Fang, W. Zhang, H. Huang, Y. Gan, Y. Xia, C. Liang, J. Zhang and X. Tao, Nano Energy, 2017, 37, 177-186.

93 C. Yang, L. Zhang, B. Liu, S. Xu, T. Hamann, D. McOwen, J. Dai, W. Luo, Y. Gong, E. D. Wachsman and L. Hu, Proc. Natl. Acad. Sci. U. S. A., 2018, 115, 3770-3775.

94 S. Xu, D. W. McOwen, C. Wang, L. Zhang, W. Luo, C. Chen, Y. Li, Y. Gong, J. Dai, Y. Kuang, C. Yang, T. R. Hamann, E. D. Wachsman and L. Hu, Nano Lett., 2018, 18, 3926-3933.

95 H. Zhao, D. Lei, Y.-B. He, Y. Yuan, Q. Yun, B. Ni, W. Lv, B. Li, Q.-H. Yang, F. Kang and J. Lu, Adv. Energy Mater., 2018, 8, 1800266.

96 P. Yao, Q. Chen, Y. Mu, J. Liang, X. Li, X. Liu, Y. Wang, B. Zhu and J. Zhu, Mater. Chem. Front., 2019, 3, 339-343.

97 W. Deng, X. Zhou, Q. Fang and Z. Liu, Adv. Energy Mater., 2018, 8, 1703152.

98 L. Porz, T. Swamy, B. W. Sheldon, D. Rettenwander, T. Frömling, H. L. Thaman, S. Berendts, R. Uecker, W. C. Carter and Y.-M. Chiang, Adv. Energy Mater., 2017, 7, 1701003.

99 X. Fan, L. Chen, X. Ji, T. Deng, S. Hou, J. Chen, J. Zheng, F. Wang, J. Jiang, K. Xu and C. Wang, Chem, 2018, 4, 174185.

100 J. Qian, W. A. Henderson, W. Xu, P. Bhattacharya, M. Engelhard, O. Borodin and J.-G. Zhang, Nat. Commun., 2015, 6, 6362.

101 Y. Lu, Z. Tu and L. A. Archer, Nat. Mater., 2014, 13, 961.

102 W. Liu, W. Li, D. Zhuo, G. Zheng, Z. Lu, K. Liu and Y. Cui, ACS Cent. Sci., 2017, 3, 135-140.

103 K. Liu, A. Pei, H. R. Lee, B. Kong, N. Liu, D. Lin, Y. Liu, C. Liu, P.-c. Hsu, Z. Bao and Y. Cui, J. Am. Chem. Soc., 2017, 139, 4815-4820.

104 S. Liu, A. Wang, Q. Li, J. Wu, K. Chiou, J. Huang and J. Luo, Joule, 2018, 2, 184-193.

105 Y. Liu, D. Lin, Z. Liang, J. Zhao, K. Yan and Y. Cui, Nat. Commun., 2016, 7, 10992.

106 J. Zhao, G. Zhou, K. Yan, J. Xie, Y. Li, L. Liao, Y. Jin, K. Liu, P.-C. Hsu, J. Wang, H.-M. Cheng and Y. Cui, Nat. Nanotechnol., 2017, 12, 993. 
107 G. Zheng, S. W. Lee, Z. Liang, H.-W. Lee, K. Yan, H. Yao, H. Wang, W. Li, S. Chu and Y. Cui, Nat. Nanotechnol., 2014, 9, 618.

108 E. Cha, M. D. Patel, J. Park, J. Hwang, V. Prasad, K. Cho and W. Choi, Nat. Nanotechnol., 2018, 13, 337-344.

109 K. Yan, H.-W. Lee, T. Gao, G. Zheng, H. Yao, H. Wang, Z. Lu, Y. Zhou, Z. Liang, Z. Liu, S. Chu and Y. Cui, Nano Lett., 2014, 14, 6016-6022.

110 B. Zhu, Y. Jin, X. Hu, Q. Zheng, S. Zhang, Q. Wang and J. Zhu, Adv. Mater., 2017, 29, 1603755.

111 X. Liang, Q. Pang, I. R. Kochetkov, M. S. Sempere, H. Huang, X. Sun and L. F. Nazar, Nat. Energy, 2017, 2, 17119.

112 W. Zhang, H. L. Zhuang, L. Fan, L. Gao and Y. Lu, Sci. Adv., 2018, 4, eaar4410.

113 L. Fan, H. L. Zhuang, W. Zhang, Y. Fu, Z. Liao and Y. Lu, Adv. Energy Mater., 2018, 8, 1703360.

114 D. Lin, Y. Liu, Z. Liang, H.-W. Lee, J. Sun, H. Wang, K. Yan, J. Xie and Y. Cui, Nat. Nanotechnol., 2016, 11, 626.

115 Y. Zhang, W. Luo, C. Wang, Y. Li, C. Chen, J. Song, J. Dai, E. M. Hitz, S. Xu, C. Yang, Y. Wang and L. Hu, Proc. Natl. Acad. Sci. U. S. A., 2017, 114, 3584-3589.

116 A. M. Hafez, Y. Jiao, J. Shi, Y. Ma, D. Cao, Y. Liu and H. Zhu, Adv. Mater., 2018, 30, 1802156.

117 D. Aurbach, E. Zinigrad, Y. Cohen and H. Teller, Solid State Ionics, 2002, 148, 405-416.
118 C. Yang, K. Fu, Y. Zhang, E. Hitz and L. Hu, Adv. Mater., 2017, 29, 1701169.

119 X. Chen, T.-Z. Hou, B. Li, C. Yan, L. Zhu, C. Guan, X.-B. Cheng, H.-J. Peng, J.-Q. Huang and Q. Zhang, Energy Storage Materials, 2017, 8, 194-201.

120 S. Bai, Y. Sun, J. Yi, Y. He, Y. Qiao and H. Zhou, Joule, 2018, 2, 2117-2132.

121 P. Yao, B. Zhu, H. Zhai, X. Liao, Y. Zhu, W. Xu, Q. Cheng, C. Jayyosi, Z. Li, J. Zhu, K. M. Myers, X. Chen and Y. Yang, Nano Lett., 2018, 18, 6113-6120.

122 H. Zhai, P. Xu, M. Ning, Q. Cheng, J. Mandal and Y. Yang, Nano Lett., 2017, 17, 3182-3187.

123 X. Han, Y. Gong, K. Fu, X. He, G. T. Hitz, J. Dai, A. Pearse, B. Liu, H. Wang, G. Rubloff, Y. Mo, V. Thangadurai, E. D. Wachsman and L. Hu, Nat. Mater., 2016, 16, 572.

124 K. Ogata, E. Salager, C. J. Kerr, A. E. Fraser, C. Ducati, A. J. Morris, S. Hofmann and C. P. Grey, Nat. Commun., 2014, 5, 3217.

125 Y. Jin, L. Zhou, J. Yu, J. Liang, W. Cai, H. Zhang, S. Zhu and J. Zhu, Proc. Natl. Acad. Sci. U. S. A., 2018, 115, 11168-11173. 126 Y. Li, Y. Li, A. Pei, K. Yan, Y. Sun, C.-L. Wu, L.-M. Joubert, R. Chin, A. L. Koh, Y. Yu, J. Perrino, B. Butz, S. Chu and Y. Cui, Science, 2017, 358, 506-510.

127 Q. Cheng, L. Wei, Z. Liu, N. Ni, Z. Sang, B. Zhu, W. Xu, M. Chen, Y. Miao, L.-Q. Chen, W. Min and Y. Yang, Nat. Commun., 2018, 9, 2942. 